\title{
Optimal retirement planning with a focus on single and joint life annuities
}

\author{
Bell, Agnieszka Karolina Konicz; Pisinger, David; Weissensteiner, Alex
}

\section{Published in:}

Quantitative Finance

Link to article, DOI:

$10.1080 / 14697688.2015 .1114361$

Publication date:

2016

Document Version

Peer reviewed version

Link back to DTU Orbit

Citation (APA):

Bell, A. K. K., Pisinger, D., \& Weissensteiner, A. (2016). Optimal retirement planning with a focus on single and joint life annuities. Quantitative Finance, 16(2), 275-295. https://doi.org/10.1080/14697688.2015.1114361

\section{General rights}

Copyright and moral rights for the publications made accessible in the public portal are retained by the authors and/or other copyright owners and it is a condition of accessing publications that users recognise and abide by the legal requirements associated with these rights.

- Users may download and print one copy of any publication from the public portal for the purpose of private study or research.

- You may not further distribute the material or use it for any profit-making activity or commercial gain

- You may freely distribute the URL identifying the publication in the public portal

If you believe that this document breaches copyright please contact us providing details, and we will remove access to the work immediately and investigate your claim. 


\title{
Optimal retirement planning with a focus on single and multilife annuities
}

\author{
Agnieszka Karolina Konicz* \\ agko@dtu.dk
}

\author{
David Pisinger \\ dapi@dtu.dk
}

\author{
Alex Weissensteiner \\ alwe@dtu.dk
}

April 18, 2014

\begin{abstract}
We optimize the asset allocation, consumption and bequest decisions of an investor with uncertain lifetime and under time-varying investment opportunities. The asset menu is given by stocks, zero coupon bonds and pure endowments with different maturities. The latter are contingent on either a single or a joint life, and pay fixed or variable benefits. We further include transaction costs on stocks and bonds, and surrender charges on pure endowments. We show that despite high surrender charges, annuities are the primary asset class in a portfolio, and that annuity income is never fully consumed, but used for rebalancing purposes. We argue that the optimal retirement product for a household is much more complex than any of those available in the market. Every household should be offered an annuity tailored to its needs, using a unique combination of assets and mortality protection levels.
\end{abstract}

\section{Introduction}

Annuities are the only investment vehicles that provide income for life, no matter how long one lives. This unique feature attracts many individuals who try to structure their income during retirement. In some countries the purchase of annuities has even been (or still is) mandatory ${ }^{1}$ In other countries no one is forced to buy them, though having an annuity is highly recommended as well as advertised.

Purchasing an annuity is not an easy task for a number of reasons. First, this decision concerns a significant amount of money. Second, it is the annuity provider who upon the individual's death inherits the potential residual wealth. Third, annuities have high surrender charges if sold before maturity. Fourth, there are so many different annuity products in the market that individuals simply do not know which product to buy ${ }^{2}$ An annuity purchase decision is not just a question of whether or not to buy an annuity. It is a question of buying the right one. Should the individuals purchase a whole life annuity or maybe a temporary annuity that provides the income only for a designated period? Should the annuity cover a single life or maybe both the wife's and the husband's joint life? What about the bequest? Is it worth to invest in an annuity with some guaranteed period?

\footnotetext{
${ }^{*}$ Corresponding author at: DTU Management Engineering, Management Science, Technical University of Denmark, Produktionstorvet 426, 2800 Kgs. Lyngby, Denmark. Tel.: +45 4525 3109; Fax: +45 4525 3435; email: agko@dtu.dk

${ }^{1}$ For example, UK had the compulsory annuity purchase until April 2011.

${ }^{2}$ See e.g. Annuity Shopper at http://www.immediateannuities.com/pdfs/as/annuity-shopper-2013-10.pdf
} 
Not surprisingly, having carefully built up the savings, the individuals find an annuity purchase to be one of the most important financial decisions, and definitely worth seeking professional advice. However, such an advice can be costly and is rarely based on optimization approaches. An alternative is to use different rules of thumb for retirement planning. For example, diversify the portfolio such that the percentage of bonds is equal to the individual's age, or withdraw 4 percent of the retirement savings each year during retirement.

The purpose of this paper is to propose an optimization model that helps individuals to invest their retirement savings. The optimal asset allocation includes stocks, bonds and pure endowments with different maturities. The latter are contingent on either a single or a joint life, and pay either fixed or variable benefits. These basic products allow us to replicate more complex annuity products, such as temporary and whole life annuities, deferred annuities, and annuities with a guaranteed period. The objective in our model is to maximize the expected utility of consumption (for either a one-person or a two-person household) during the retirement period, given the individual's risk aversion, personal preferences, lifetime expectancy, and the bequest motive.

Although several studies have discussed the investment strategies that include annuities, they all focus on the distribution between stocks, bonds, and either whole life fixed or variable annuity products. Very few studies investigate the preferences between single and multilife annuities, and none of the studies tries to exploit other annuity options such as the preferences between the temporary and the whole life annuities, or life annuities with a guaranteed period. In other words, scholars have paid far too little attention to advise the individuals which annuity product fits best to their needs.

Yaari (1965) was the first to show that the individuals gain from investing in annuities, and in particular, if no bequest is present, they should choose annuities rather than bonds. Milevsky and Young (2007) argue that even in the presence of a bequest motive individuals should hold some fixed annuities, and the proportion in the annuities should increase with the level of risk aversion. Horneff et al. (2008), moreover, show that the optimal stock fraction follows the well-known life-cycle pattern with the shift towards fixed annuities instead of bonds, and that bonds should be chosen only in the case of a substantial bequest motive. Horneff et al. (2009) extend this work by including variable annuities and argue that the attractiveness of these products lies in their high expected return consisting of an equity premium as well as a survival credit. Another class of annuities investigated in the recent years are deferred annuities. Both Scott et al. (2007) and Horneff et al. (2010) show that households benefit substantially from holding this type of annuities in their portfolios. Finally, the retirement plan for households is also a subject of investigation in Hubener et al. (2014), who show that retired couples should primarily invest in joint and survivor annuities.

The aforementioned studies tend to focus on finding the explicit solution for the optimal consumption and portfolio allocation problems. However, in order to keep analytical tractability, one must assume a relatively simple model. Therefore, these studies do not implement transaction costs or surrender charges, and they assume bonds to be risk free. In this paper we apply a multi-stage stochastic programming (MSP) approach, known for its practical applications, see e.g. Mulvey et al. (2003) and Mulvey et al. (2008) for the application in defined benefit pension plans, or Ferstl and Weissensteiner (2011) and Konicz and Mulvey (2013) for the application in the field of individual asset liability management. This numerical method allows to obtain the optimal solution under realistic assumptions. We consider time-varying investment opportunities with a vector-autoregressive model. Based on the joint evolution of the term structure and the stock market, we generate the scenario trees using the approach in Høyland and Wallace (2001) and Høyland et al. (2003), 
by matching the first four moments and the correlations of the underlying processes. Another advantage of choosing a stochastic programming approach is to add constraints on the asset allocation and on personal preferences. Furthermore, we consider transaction costs on stocks and bonds, and surrender charges on pure endowments and annuities. The latter are the penalties for selling the life contingent products before maturity.

Our findings regarding the optimal asset allocation support the results obtained by the aforementioned studies, i.e. the allocation between the liquid and illiquid assets, and between the assets with different financial risk, highly depends on the bequest motive and the level of risk aversion. However, in contrast to other studies, our findings also exploit different annuity options. Among other conclusions, we show that despite high surrender charges, households diversify their portfolios by investing in a wide variety of pure endowments and annuities. They spend only a fraction of the life contingent income for consumption, and use the residual amount to rebalance the portfolio. Finally, households hold the largest number of different products and gain especially from investing in variable joint and survivor pure endowments as well as in variable pure endowments contingent on the husband's life. We summarize by arguing that the right annuity for a household is much more complex than any of those available in the market, and therefore annuity providers should design the products highly customized to the household's needs.

The structure of the paper is as follows. Sections 2 and 3 describe the general model setup, available assets, and details regarding the model uncertainty. Section 4 presents and explains the multi-stage stochastic model together with its objective function and the constraints. Section 5 analyzes the numerical results, and Section 6 concludes.

\section{Model description}

Throughout the paper, we use capital letters to denote stochastic values (variables) as opposed to the lowercase letters denoting the parameters for the model.

We seek for the optimal consumption, investment and amount of bequest for the individuals and couples upon retirement. To calculate optimal decisions, we follow a classical approach, e.g. Richard (1975), and maximize the expected utility of consumption and bequest during retirement, given uncertain lifetime of an individual,

$$
\max E\left[\sum_{t=t_{0}}^{T}{ }_{t} p_{x} u\left(t, C_{t}\right)+\sum_{t=t_{0}}^{T-1}{ }_{t} p_{x} q_{x+t} k u\left(t, W_{t}\right)\right],
$$

where $u$ is a utility function with constant relative risk aversion (CRRA) equal to $1-\gamma$ and a time preference (impatience) factor $\rho$

$$
u\left(t, C_{t}\right)=\frac{1}{\gamma} e^{-\rho t} C_{t}^{\gamma}
$$

We assume the same utility function for consumption $C_{t}$ and bequest $W_{t}$ with the scalar $k$ reflecting the strength of the bequest motive relative to consumption. The value of bequest $W_{t}$ is equal to the value of non-life contingent assets, i.e. stocks and bonds. Furthermore, we multiply the utility of consumption by the survival probability of an $x$-year old person ${ }_{t} p_{x}$ and the utility of bequest by the probability that an $x$-year 
old person survives until time $t$ but dies during the following period ${ }_{t} p_{x} q_{x+t}$. Such an objective function is a special case of Richard (1975), and it has been considered in e.g. Konicz and Mulvey (2014).

For a two-person household, we maximize the expected consumption of two individuals. The objective further captures different possibilities for the bequest motive, depending on whether the bequest is for the children (or other dependants) or specifically for the spouse. If the couple has a bequest motive for their children, they choose a positive $k$, and upon death the dependants receive the value of the portfolio invested in stocks and bonds, $W_{t}$. If the objective is to bequeath to one of the spouses, the couple chooses positive $k^{(x)}$ and/or $k^{(y)}$, corresponding to the bequest for the wife $(x)$ and/or the husband $(y)$. Thus, we extend the objective suggested in Bruhn and Steffensen (2011), and introduce the following objective function

$$
\begin{aligned}
\max & E\left[\sum_{t=t_{0}}^{T}{ }_{t} p_{x: y} u\left(t, C_{t}\right)+\sum_{t=t_{0}}^{T-1}{ }_{t} p_{x: y} q_{\overline{x+t: y+t}} k u\left(t, W_{t}\right)\right. \\
+ & \left.\sum_{t=t_{0}}^{T-1}{ }_{t} p_{x: y}\left(p_{x+t} q_{y+t} k^{(x)} u\left(t, W_{t}+A_{t}^{(x)}\right)+q_{x+t} p_{y+t} k^{(y)} u\left(t, W_{t}+A_{t}^{(y)}\right)\right)\right],
\end{aligned}
$$

where in line with the International Actuarial Notation ${ }_{t} p_{x: y}$ denotes the joint survival probability until time $t$ of the $x$-year old wife and the $y$-year old husband, and $q_{\overline{x+t: y+t}}$ denotes that both the $x+t$-year old wife and the $y+t$-year old husband die during the following period. We assume that the lives of the spouses are independent, thus ${ }_{t} p_{x: y}={ }_{t} p_{x}{ }_{t} p_{y}$ and $q_{\overline{x+t: y+t}}=q_{x+t} q_{y+t}$, where the probabilities ${ }_{t} p_{x}$ and ${ }_{t} p_{y}$ correspond to the survival probabilities of the wife and the husband, respectively, and $q_{x+t}$ and $q_{y+t}$ correspond to death probabilities during the following period. Upon the wife's death the husband inherits stocks and bonds as well as life annuities contingent on his life $W_{t}+A_{t}^{(y)}$, upon the husband's death the wife inherits stocks and bonds as well as life annuities contingent on her life $W_{t}+A_{t}^{(x)}$, and upon the death of both spouses other dependants inherit $W_{t}$.

\subsection{Available assets}

Because annuities play the most important role in retirement planning we start with explaining their payout options. We choose to refer to annuities simply as "a sum of money payable yearly or at other regular intervals", see Dellinger (2006). Depending on the conditions under which this sum is paid, we categorize annuities into the following categories: number of lives covered, payout option, first payment date, and benefit measure, pattern, and frequency.

In fact, all annuity payout options can be replicated by a combination of four basic financial products: a zero coupon bond, a pure endowment, a 100\% joint and surivivor (JESS) pure endowment, and a variable pure endowment. While a zero coupon bond has a guaranteed payment of $£ 1$ at maturity $M$, independently whether the annuitant is alive, the payment of $£ 1$ of a pure endowment is conditional on the life of the annuitant. A $100 \% \mathrm{~J} \& \mathrm{~S}$ pure endowment pays $£ 1$ at time $M$ if at least one of the annuitants is alive. Finally, conditionally on the life of the annuitant, a variable pure endowment pays a variable benefit at time $M$. Therefore, our assets menu consists of stocks, bonds and pure endowments, where the latter are contingent on either a single or a joint life, and pay fixed or variable benefits.

Having access to these four basic assets, we can define a wide range of annuities, see Fig. 1. For example, depending on the number of lives covered, we distinguish between: 
- Single Life Annuities - payout is linked to the survival of an individual.

- $Y \%$ Joint and Survivor (J\&S) Annuities - payout is linked to the survival of two lives. After the first death of either annuitant, the annuity pays $Y \%$ of the initial benefit as long as the survivor is alive.

Independently of the number of lives covered, the annuities can be further classified based on their different payout options such as the designated period and the guaranteed period:

- Whole Life Annuities - pay as long as the annuitant is alive.

- Term (or Temporary) Life Annuities - pay for the shorter of $M$ years or the life of the annuitant. Typically, $M=\{10,15,20,25\}$ years.

- Life Annuities with $X$ Years Guaranteed - pay as long as the annuitant is alive. If he dies within the first $X$ years, payments continue to the dependants until the end of the $X^{\text {th }}$ year.

We also distinguish between fixed and variable annuities:

- Fixed Annuities - pay fixed benefits that are fully specified upon the purchase of the contract. These benefits are typically constant or increasing.

- Variable Annuities - pay the benefits that are unknown upon the purchase of the contract. The level of payments changes depending on the returns on the portfolio that backs the annuity.

Finally, we categorize the annuities by the time of the initial payment:

- Immediate Annuities - payments commence on purchase of the annuity.

- Deferred Annuties - payments commence at some future date.
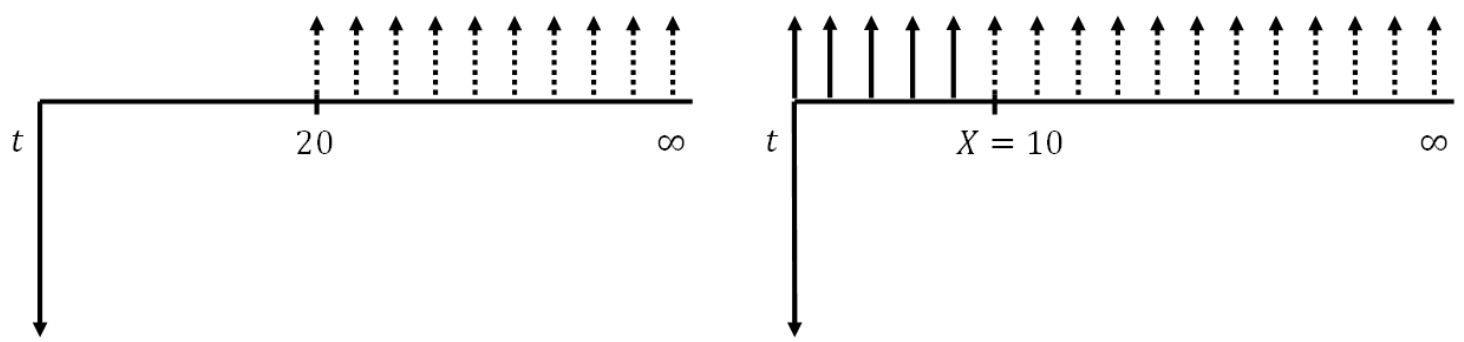

Figure 1: Annuity cash flow. A cash flow from a whole life annuity deferred 20 years (left figure) can be replicated by a number of pure endowments with the shortest maturity equal to the time of the first payment, and the longest maturity equal to $\infty$. In practice the annuity providers assume that individuals are dead with probability one upon age 120 , thus the maturity date for the last pure endowment is set to the 120th birthday of the annuitant. A cash flow from an immediate annuity with $X=10$ years guaranteed (right figure) can be replicated by a combination of zero coupon bonds with the maturities $M<X$, and pure endowments with $M \geq X$. The continuous line arrows indicate the certain payment, whereas the dashed line arrows indicate that the payment is conditional on the annuitant's survival. 


\subsection{Prices and cash flows}

The price at time $t$ of a zero coupon bond with maturity $M$ is given by,

$$
\operatorname{price}_{t}^{b}=\left(\frac{1}{1+r(t, M)}\right)^{M-t},
$$

where $r(t, M)$ is the interest rate from $t$ to $M$.

The price of the pure endowment is based on the mortality rates. Because the date of death is unknown, the insurer uses mortality tables, from which the probabilities of death at particular ages can be calculated 3 Therefore, the prices differ for each gender: they are higher for women than for men, simply because women on average live longer 4 The price at time $t$ of a pure endowment paying out at time $M$ conditionally on the annuitant's survival, is then given by

$$
\operatorname{price}_{t}^{(x)}={ }_{M-t} p_{x+t}\left(\frac{1}{1+r(t, M)}\right)^{M-t},
$$

and the price of the $100 \%$ J\&S pure endowment by

$$
\operatorname{price}_{t}^{100 \% J \& S}={ }_{M-t} p_{\overline{x+t: y+t}}\left(\frac{1}{1+r(t, M)}\right)^{M-t},
$$

where ${ }_{M-t} p_{\overline{x+t: y+t}}$ is the probability that at least one of the spouses survives until time $M$. We can further price the $Y \% \mathrm{~J} \& \mathrm{~S}$ pure endowments by using a linear combination of two single pure endowments and a $100 \%$ J\&S pure endowment,

$$
\operatorname{price}_{t}^{Y \% J \& S}=(1-Y)\left(\text { price }_{t}^{(x)}+\text { price }_{t}^{(y)}\right)+(2 Y-1) \text { price }_{t}^{100 \% J \& S} .
$$

Such a pure endowment pays $Y \%$ of the initial benefit as long as the survivor is alive. For example, $50 \%$ J\&S pure endowment pays $£ 1$ conditionally on the survival of both annuitants, and $£ 0.5$ conditionally on the survival of only one annuitant.

The price of the variable pure endowment is equal to the price of pure endowment. However, the payment is linked to the risky assets (e.g. 100\% in FTSE100 index), therefore uncertain. While the pure endowment pays a benefit of $£ 1$ upon maturity $M$, the variable pure endowment linked to the risky assets pays

$$
1 \cdot\left(\frac{1+h(t, M)}{1+r(t, M)}\right)^{M-t}
$$

upon maturity $M$ (both given the survival of the annuitant). The rate $h(t, M)$ is the realized return on the equity index over the period $(t, M)$, therefore first known upon time $M$, and $r(t, M)$ is the interest rate over the same period.

\footnotetext{
${ }^{3}$ In this study we use the British mortality tables based on 2000-2006 experience from UK self-administered pension schemes, published in CMI Working papers 33 and 35, 2008.

${ }^{4}$ In the last years the European Court of Justice ruled that gender may not be used in pricing of life contingent products, and since December 2012 the unisex pricing is in force according to the European law, see e.g http://www.thisismoney.co.uk/ money/pensions/article-1713762/How-EU-gender-rule-hits-your-pension.html Nevertheless, in our model we take a more general approach, and price the products according to the individual's gender, as it is still the case in many countries such as the U.S., see e.g. Annuity Shopper at http://www.immediateannuities.com/pdfs/as/annuity-shopper-2013-10.pdf.
} 


\subsection{Costs}

Costs are important when defining financial products. For stocks and bonds we assume the transaction costs to be paid both upon the purchase and the sale of the assets, $t c^{s}$ and $t c^{b}$, respectively. The costs corresponding to annuities are more complex. We distinguish between the mortality and expense charges (M\&E) and surrender charges. M\&E charge pays for the insurance guarantee, commissions, selling, and administrative expenses of the contract. We model this charge as a percentage of the investment value paid upon the purchase of the product. Surrender charges are penalties charged by the insurance company for withdrawals exceeding a certain free amount specified in the contract. Then, the amount received upon the sale of the annuity $a$, Withdraw ${ }_{t}^{a}$, is given by

$$
\text { Withdraw }_{t}^{a}= \begin{cases}\text { Free }_{t}^{a}+\left(\text { price }_{t}^{a} \text { Sell }_{t}^{a}-\text { Free }_{t}^{a}\right)\left(1-\text { sc }_{t}^{a}\right), & \text { price }_{t}^{a} \text { Sell }_{t}^{a}>\text { Free }_{t}^{a}, \\ \text { price }_{t}^{a} \text { Sell }_{t}^{a}, & \text { price }_{t}^{a} \text { Sell la }_{t}^{a} \leq \text { Free }_{t}^{a},\end{cases}
$$

where $\operatorname{price}_{t}^{a}$ Sell $_{t}^{a}$ is the market value of annuity $a$ at time $t, s c_{t}^{a}$ are the surrender charges, and Free $e_{t}^{a}$ is the free withdrawal amount determined by the rate $f w^{a}$,

$$
\text { Free }_{t}^{a}=\text { fw }_{t}^{a} \text { price }_{t}^{a} \text { Buyt } y_{t}^{a}, \quad t=t_{0},
$$

where price $_{t}^{a} B u y_{t}^{a}$ is the market value of annuity $a$ upon the purchase at time $t$. The free withdrawal amount is adjusted each time the annuitant purchases or withdraws from the same annuity,

$$
\text { Free }_{t}^{a}=\text { Free }_{t-1}^{a}+\text { fw } w_{t}^{a} \text { price }_{t}^{a} \text { Buy } y_{t}^{a}-\min \left(\text { Free }_{t-1}^{a}, \text { price }_{t}^{a} \text { Sell }_{t}^{a}\right), \quad t>t_{0} .
$$

Surrender charges $s c_{t}^{a}$ can range from $1 \%$ to $20 \%$ depending on the type of annuity, and decline with time until they reach zero 5 In this study we assume the free withdrawal rate of $f w^{a}=10 \%$, and surrender charges $s c_{t}^{a}$ as presented in Table 1 Surrender charges differ between the annuity providers, nevertheless to investigate the benefits of investing in annuities, we intentionally choose high surrender charges for our model.

\begin{tabular}{l|ccccc} 
& \multicolumn{5}{|c}{ time (years) } \\
product & 0 & 5 & 10 & 15 & 20 \\
\hline pure endowment, M5 & $5 \%$ & & & & \\
pure endowment, M10 & $10 \%$ & $5 \%$ & & & \\
pure endowment, M15 & $15 \%$ & $10 \%$ & $5 \%$ & & \\
pure endowment, M20 & $20 \%$ & $15 \%$ & $10 \%$ & $5 \%$ & \\
whole life annuity, def20 & $20 \%$ & $20 \%$ & $20 \%$ & $20 \%$ & $20 \%$ \\
\hline
\end{tabular}

Table 1: Surrender charges $s c_{t}^{a}$ for pure endowments maturing in 5, 10, 15 and 20 years and a whole life annuity deferred 20 years.

${ }^{5}$ See financial websites for private investors, e.g. http://money.cnn.com/retirement/guide/annuities_basics.moneymag/ index9.htm and http://www.fool.com/retirement/annuities/annuities02.htm 


\section{Modeling uncertainty}

The optimal retirement saving strategy depends on the uncertainty in our decision problem. While mortality risk is explicitly considered in the objective function and in the pricing of life contingent products, we propose a model for the joint evolution of the term structure of interest rates with the stock market for which a scenario tree is created. Here we focus on the UK market. We use historical zero coupon interest rates available at Bank of England's website ${ }^{6}$ and adjusted prices of the FTSE100 index from Thomson Reuters Datastream. We consider monthly data from Jan 1993 to Dec 2013.

\subsection{Term structure of interest rates}

To model the evolution of the yield curve, we propose to use the Nelson/Siegel model for two reasons. First, this parametric model can condense the entire yield curve to a few parameters. In this way the branching factor of the scenario tree can be kept low, which ensures computational tractability. Second, given that parsimonious models avoid the problem of overfitting data in-sample, these models seem to be better suited for predictions out-of-sample, see e.g. Diebold and Li (2006). Also theoretically more advanced affine term structure models, does not seem to be suited for that purpose, see e.g. Ang et al. (2007) and Coroneo et al. (2011).

The three-factor model for the spot rates can be written as:

$$
y\left(\boldsymbol{\beta}_{t}, M\right)=\beta_{1, t}+\beta_{2, t}\left(\frac{1-e^{-\lambda_{t} M}}{\lambda_{t} M}\right)+\beta_{3, t}\left(\frac{1-e^{-\lambda_{t} M}}{\lambda_{t} M}-e^{-\lambda_{t} M}\right)
$$

where $y\left(\boldsymbol{\beta}_{t}, M\right)$ indicates the yearly (continuously compounded) spot rate for maturity $M$ at stage $t$ given the parameter vector $\boldsymbol{\beta}_{t}=\left[\beta_{1, t}, \beta_{2, t}, \beta_{3, t}\right]^{\top}$ for level, slope and curvature of the term structure of interest rates. Following Diebold and Li (2006), we fix $\lambda_{t}$ at 0.4218, which minimizes the mean squared error in our data set. In this way the estimation of the remaining parameters $\beta_{1, t}, \beta_{2, t}$ and $\beta_{3, t}$ simplifies to an ordinary least square (OLS) regression. At the same time fixing $\lambda$ leads to stability of the estimated parameters over time, a property required to capture the dynamic behaviour with a stochastic model.

\subsection{Time-varying investment opportunities}

We model the time-varying investment opportunities with a VAR(1)-process. For an application in asset allocation decisions see e.g. Barberis (2000), Campbell et al. (2003), and Brandt et al. (2005), and for the combined evolution of interest rates (represented by the coefficient vector $\boldsymbol{\beta}_{t}$ ) and equity returns, see, e.g. Boender et al. (2005) and Ferstl and Weissensteiner (2011). We use the following $(K \times 1)$ parameter vector $\boldsymbol{\xi}_{t}($ with $K=4)$ :

$$
\boldsymbol{\xi}_{t}=\left[\begin{array}{c}
r_{t} \\
\boldsymbol{\beta}_{t}
\end{array}\right],
$$

where $r_{t}$ refers to the log equity return and $\boldsymbol{\beta}_{t}$ to the $(3 \times 1)$ vector of Nelson/Siegel parameters. The VAR(1) process can be written as:

$$
\boldsymbol{\xi}_{t}=\mathbf{c}+\mathbf{A} \boldsymbol{\xi}_{t-1}+\mathbf{u}_{t}
$$

\footnotetext{
${ }^{6}$ Bank of England, http://www.bankofengland.co.uk/statistics/pages/yieldcurve/default.aspx
} 
where $\mathbf{c}$ is the $(K \times 1)$ vector of intercepts, $\mathbf{A}$ is the $(K \times K)$ matrix of slope coefficients and $\mathbf{u}_{t}$ the $(K \times 1)$ vector of i.i.d. innovations with $\mathbf{u} \sim N(0, \boldsymbol{\Sigma})$. The covariance of the innovations $\boldsymbol{\Sigma}$ is given by $\mathbb{E}\left(\mathbf{u} \mathbf{u}^{\top}\right)$. Thus, we allow the shocks to be cross-sectionally correlated, but assume that they are homoskedastic and independently distributed over time. If all eigenvalues of $\mathbf{A}$ have modulus less than one, as in our empirical example below, the stochastic process in equation (14) is stable with unconditional expected mean $\boldsymbol{\mu}$ and covariance $\boldsymbol{\Gamma}$ for the steady state at $t=\infty$, see e.g. Lütkepohl (2005):

$$
\begin{aligned}
\boldsymbol{\mu}: & =(\mathbf{I}-\mathbf{A})^{-1} \mathbf{c} \\
\operatorname{vec}(\boldsymbol{\Gamma}): & =(\mathbf{I}-\mathbf{A} \otimes \mathbf{A})^{-1} \operatorname{vec}(\boldsymbol{\Sigma}),
\end{aligned}
$$

where $\mathbf{I}$ refers to the identity matrix, the symbol $\otimes$ is the Kronecker product and "vec" transforms a $(K \times K)$ matrix into a $\left(K^{2} \times 1\right)$ vector by stacking the columns.

\begin{tabular}{lcccccc}
\hline & $r_{t-1}$ & $\beta_{1, t-1}$ & $\beta_{2, t-1}$ & $\beta_{3, t-1}$ & $c$ & $R^{2}$ \\
\hline$r_{t}$ & 0.0168 & 0.1827 & -0.0566 & -0.0464 & -0.0077 & 0.0099 \\
$(t$-value $)$ & $(0.2633)$ & $(0.9175)$ & $(-0.3906)$ & $(-0.4548)$ & $(-0.7485)$ & \\
$\beta_{1, t}$ & -0.0025 & 0.9537 & -0.0136 & 0.0145 & 0.0022 & 0.9689 \\
$(t$-value $)$ & $(-0.5894)$ & $(72.2721)$ & $(-1.4129)$ & $(2.1377)$ & $(3.1581)$ & \\
$\beta_{2, t}$ & 0.0181 & 0.0357 & 0.9912 & 0.0093 & -0.0022 & 0.9715 \\
$(t$-value $)$ & $(2.8948)$ & $(1.8239)$ & $(69.6406)$ & $(0.9316)$ & $(-2.1291)$ & \\
$\beta_{3, t}$ & -0.0126 & 0.0452 & 0.0196 & 0.9582 & -0.0022 & 0.9405 \\
$(t$-value $)$ & $(-1.0655)$ & $(1.2231)$ & $(0.7267)$ & $(50.5729)$ & $(-1.1514)$ & \\
\hline
\end{tabular}

Table 2: VAR(1) parameters and $t$-statistics for monthly data from Jan 1993 to Dec 2013.

The estimated parameters and the values for the $t$-statistics are reported in Table 2 . All modulus of the eigenvalues of the characteristic polynomial are below one. The monthly Nelson/Siegel coefficients $\beta_{i, t-1}$ are highly persistent as well as statistically significant.

\begin{tabular}{ccccc}
\hline & $r$ & $\beta_{1}$ & $\beta_{2}$ & $\beta_{3}$ \\
\hline$r$ & 4.0900 & -0.0770 & 0.0860 & -0.0066 \\
$\beta_{1}$ & -0.0770 & 0.2710 & -0.7383 & -0.2168 \\
$\beta_{2}$ & 0.0860 & -0.7383 & 0.4016 & 0.0271 \\
$\beta_{3}$ & -0.0066 & -0.2168 & 0.0271 & 0.7594 \\
\hline
\end{tabular}

Table 3: Cross correlations and standard deviations of residuals for monthly data from Jan 1993 to Dec 2013.

While Table 3 illustrates monthly standard deviations (multiplied by 100) on the main diagonal and cross correlations of residuals above it, in Table 4 we indicate the unconditional expected mean $\boldsymbol{\mu}$ of the VAR parameters in the steady state. The expected return for equities equals $5.7 \%$ p.a., while the term structure of interest rates (continuously compounded) given by the Nelson/Siegel parameters is increasing and concave as shown in Figure 2 .

\begin{tabular}{ccccc}
\hline & $r$ & $\beta_{1}$ & $\beta_{2}$ & $\beta_{3}$ \\
\hline 1 & 0.0047 & 0.0526 & -0.0368 & -0.0143 \\
\hline
\end{tabular}

Table 4: Unconditional expected values $\boldsymbol{\mu}$ for the steady state. 


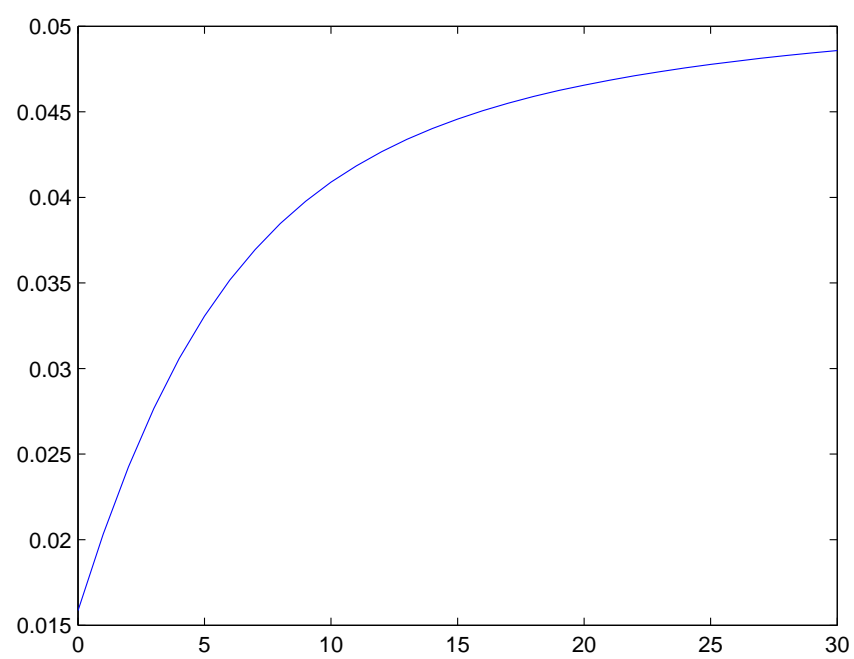

Figure 2: Term structure of interest rates for the steady state.

A scenario tree approximates the discrete-time multivariate process in equation (14) with a few mass points at each stage. Therefore, we use the technique proposed by Høyland and Wallace (2001) and Høyland et al. (2003) to match the first four moments and the correlations with a branching factor of 10. To uncouple our results from a particular root note, we start our tree construction from the unconditional expected values as done by e.g. Campbell et al. (2003) and Ferstl and Weissensteiner (2011). Given that we use 5-year decision steps with a VAR process calibrated on monthly data, we follow Pedersen et al. (2013) to calculate the aggregated asset returns between two decision stages. The annuity products are priced with the corresponding yields extracted from the $\boldsymbol{\beta}$ factors.

\begin{tabular}{rrrrrrr}
\hline & $5 y$ & $10 \mathrm{y}$ & $15 \mathrm{y}$ & $20 \mathrm{y}$ & $25 \mathrm{y}$ & $30 \mathrm{y}$ \\
\hline$p_{z}=0.1$ & 0.0057 & 0.0195 & 0.0261 & 0.0290 & 0.0305 & 0.0315 \\
$p_{z}=0.5$ & 0.0325 & 0.0403 & 0.0442 & 0.0461 & 0.0474 & 0.0482 \\
$p_{z}=0.9$ & 0.0620 & 0.0630 & 0.0636 & 0.0643 & 0.0655 & 0.0661 \\
\hline
\end{tabular}

Table 5: Percentiles of the yield curve for different maturities at the final stage.

In Table 5 we test the plausibility of the yield curves in our scenario tree. We give percentiles of spot rates with different maturities for cumulative probabilities $p_{z}$, with $p_{z} \in\{0.1,0.5,0.9\}$ at the final decision stage. In addition, to show that most yields lie within a meaningful range, Table 5 illustrates that the variability is higher for short-rate yields - a well-known stylized fact.

\section{MSP formulation}

Given the generated scenario trees with the term structure of interest rates and the stock returns, we can now formulate the optimization module of the problem. We define the following sets: $\mathcal{N}_{t}$ - the set of nodes at period $t, \mathcal{S}$ - the set of stocks, $\mathcal{B}$ - the set of bonds, and $\mathcal{A}$ - the set of pure endowments and annuities. 
We specify the subsets of $\mathcal{A}$ as follows: $\mathcal{A}^{\text {whole life }}$ is a set of the whole life annuities with fixed payments. In the single case this subset includes only the whole life annuity contingent on the wife's life. In the case of a household, this subset includes two whole life annuities contingent on the wife's and the husband's life, respectively. The subsets $\mathcal{A}^{l i f e, x}$ and $\mathcal{A}^{l i f e, y}$ include pure endowments and annuities contingent on the wife's life and on the husband's life, respectively, and the $100 \% \mathrm{~J} \& \mathrm{~S}$.

We further define the model parameters and the variables, as shown in Table 6 Each variable starts with a capital letter and has a subscript $\{t, n\}$ implying that its value depends on the node $n$ and stage $t$. Subscript $\left\{t^{-}, n^{-}\right\}$denotes the predecessor of node $n \in \mathcal{N}_{t}$.

\subsection{A one-person household model}

The objective is to maximize the expected utility of consumption and bequest given uncertain lifetime. In our discrete time and state framework the objective function defined in (1) is given by,

$$
\max \sum_{t=t_{0}}^{T} \sum_{n \in \mathcal{N}_{t}}{ }_{t} p_{x} \alpha_{t, n} u\left(t, C_{t, n}\right) \cdot \operatorname{prob}_{n}+\sum_{t=t_{0}}^{T-1} \sum_{n \in \mathcal{N}_{t}}{ }_{t} p_{x} q_{x+t} k u\left(t, W_{t, n}\right) \cdot \operatorname{prob}_{n},
$$

where

$$
\alpha_{t, n}= \begin{cases}\sum_{s=t}^{t+\Delta t}{ }_{s-t} p_{x+t} e^{-r(t, s)(s-t)}, & t<T \\ \sum_{s=t}^{\infty}{ }_{s-t} p_{x+t} e^{-r(t, s)(s-t)}, & t=T\end{cases}
$$

Variable $C_{t}$ denotes the yearly consumption, thus to allow the periods between the stages, $\Delta t$, to be longer than one year, we multiply the utility of consumption by $\alpha_{t, n}$. In this way we consider that the investor does not consume only at the stages $t$, but also during the subsequent time intervals. Adding the multiplier $\alpha_{t, n}$ is particularly important upon the horizon $T$ to ensure that the individual has enough savings and will never outlive his wealth.

The budget constraint (19) controls all the incoming and outgoing payments. The portfolio is self financing, i.e. there is no other exogenous income than the initial savings $w_{0}$ at time $t_{0}$. At each period, the individual uses some of the savings for consumption. The purchase of new assets is financed from the cash flows obtained from bonds and annuities purchased in the previous periods, and from selling assets. Rebalancing bonds and stocks entails transaction costs, $t c^{b}$ and $t c^{s}$. The fees related to annuities are more complex and consist of the $m e^{a}$ charge paid upon the purchase of an annuity, and the surrender charges $s c_{t}^{a}$ paid upon the sale. For $t=t_{0}, \ldots, T-1, n \in \mathcal{N}_{t}$ we have

$$
\begin{aligned}
\alpha_{t, n} C_{t, n} & =w_{0} 1_{\left\{t=t_{0}\right\}} \\
& +\sum_{a \in \mathcal{A}} \text { Vithdraw }_{t, n}^{a}-\sum_{a \in \mathcal{A}} \operatorname{price}_{t, n}^{a} \text { Buy }_{t, n}^{a}\left(1+m e^{a}\right)+\sum_{a \in \mathcal{A}} c f_{t, n}^{a} \operatorname{Hold}_{t, n}^{a} \\
& +\sum_{b \in \mathcal{B}} \operatorname{price}_{t, n}^{b} \operatorname{Sell}_{t, n}^{b}\left(1-t c^{b}\right)-\sum_{b \in \mathcal{B}} \operatorname{price}_{t, n}^{b} B u y_{t, n}^{b}\left(1+t c^{b}\right)+\sum_{b \in \mathcal{B}} c f_{t, n}^{b} \operatorname{Hold}_{t, n}^{b} \\
& +\operatorname{price}_{t, n}^{s} \operatorname{Sell}_{t, n}^{s}\left(1-t c^{s}\right)-\operatorname{price}_{t, n}^{s} \text { Buy }_{t, n}^{s}\left(1+t c^{s}\right),
\end{aligned}
$$

where $1_{\{t=(\cdot)\}}$ denotes the indicator function equal to 1 if $t=(\cdot)$, and 0 otherwise.

To implement the surrender charges using linear constraints, it is necessary to rewrite (9)-(11) in the 


Parameters
$c f_{t}^{a}\left(c f_{t}^{b}\right)$
$p r i c e_{t, n}^{a}\left(\right.$ price $_{t, n}^{b}$, price $\left._{t, n}^{s}\right)$
$m e^{a}$
$s c_{t}^{a}$
$t c^{b}\left(t c^{s}\right)$
$f w^{a}$
$w_{0}$
$\left.k{ }^{(x)}, k^{(y)}\right)$
${ }_{t} p_{x}\left({ }_{t} p_{y}\right)$
$q_{x+t}\left(q_{y+t}\right)$
${ }_{t} p_{x: y}$
$q_{\overline{x+t: y+t}}$
${ }_{p r o b}$
$\alpha_{n, t}$

\section{Variables}

$B u y_{t, n}^{a}\left(B u y_{t, n}^{b}, B u y_{t, n}^{s}\right)$

$\operatorname{Sell}_{t, n}^{a}\left(\operatorname{Sell}_{t, n}^{b}, \operatorname{Sell}_{t, n}^{s}\right)$

$\operatorname{Hold}_{t, n}^{a}\left(\operatorname{Hold}_{t, n}^{b}, \operatorname{Holds}_{t, n}^{s}\right)$

$W_{t, n}$

$C_{t, n}$

$A_{t, n}^{(x)}\left(A_{t, n}^{(y)}\right)$

Free $_{t, n}^{a}$ Withdraw $w_{t, n}^{a}$

$Y_{t, n}^{a+}, Y_{t, n}^{a-}$ cash flow generated by pure endowment/annuity $a$ (bond $b$ ) at time $t$, price of pure endowment/annuity $a$ (bond $b$, stock $s$ ) at time $t$, node $n$, $\mathrm{M} \& \mathrm{E}$, mortality and expense charge for pure endowment/annuity $a$, surrender charge on pure endowment/annuity $a$, at time $t$, transaction costs for bond $b$, stock $s$, percentage rate of a free withdrawal on pure endowment/annuity $a$, initial savings,

weight on the bequest motive for the heirs (wife, husband), survival probability of an $x$-year old wife until age $x+t$ (y-year old husband until age $y+t$ ),

probability that an $x+t$-year old wife ( $y+t$-year old husband) dies during the following period,

joint survival probability of the $x$-year old wife and the $y$-year old husband until ages $x+t$ and $y+t$,

probability that both $x+t$-year old wife and $y+t$-year old husband die during the following period,

probability of node $n$,

multiplier for the utility of consumption at node $n$, stage $t$,

units of pure endowment/annuity $a$ (bond $b$, stock $s$ ) purchased at time $t$, node $n$, units of pure endowment/annuity $a$ (bond $b$, stock $s$ ) sold at time $t$, node $n$,

units of pure endowment/annuity $a$ (bond $b$, stock $s$ ) held at time $t$, node $n$, Hold $t_{t_{0}^{-}, n_{0}^{-}}^{a}=H_{\text {old }} d_{t_{0}^{-}, n_{0}^{-}}^{b}=H_{\text {old }} t_{t_{0}^{-}, n_{0}^{-}}=0$,

total wealth (after rebalancing) in bonds and stocks at time $t$, node $n$, consumption at time $t$, node $n$,

wealth in pure endowments/annuities contingent on the wife's (husband's) life at time $t$, node $n$,

free withdrawal amount on pure endowment/annuity $a$, actual amount received from the sales of pure endowment/annuity $a$ at time $t$, node $n$, auxiliary variables for pure endowment/annuity $a$.

Table 6: Parameters and variables for the multi-stage stochastic program. 
following way:

$$
\begin{aligned}
\text { price }_{t, n}^{a} \text { Sell }_{t, n}^{a}+Y_{t, n}^{a+} & =\text { Free }_{t, n}^{a}+Y_{t, n}^{a-} \\
\text { Free }_{t, n}^{a} & =\text { fw }^{a} \text { price }_{t, n}^{a} B u y_{t, n}^{a}+Y_{t^{-}, n^{-}}^{a+} \\
\text { Withdraw }_{t, n}^{a} & =\text { price }_{t, n}^{a} \text { Sell }_{t, n}^{a}-Y_{t, n}^{a-} \text { sc }_{t}^{a} \\
Y_{t, n}^{a+} & \geq 0, \quad Y_{t, n}^{a-} \geq 0, \quad \text { Free }_{t, n}^{a} \geq 0,
\end{aligned}
$$

for $t=t_{0}, \ldots, T, n \in \mathcal{N}_{t}$. In this reformulation, we have introduced two auxiliary variables $Y_{t, n}^{a+}$ and $Y_{t, n}^{a-}$, only one of which is positive at each node $n$. If the individual sells the value of annuities that is less or equal the free withdrawal amount, rrice $_{t, n}^{a}$ Sell $_{t, n}^{a}-$ Free $_{t, n}^{a} \leq 0$, then $Y_{t, n}^{a+} \geq 0$ and $Y_{t, n}^{a-}=0$, and no costs are charged. If the individual sells more than the free withdrawal amount, $\operatorname{price}_{t, n}^{a} \operatorname{Sell}_{t, n}^{a}-$ Free $_{t, n}^{a}>0$, then $Y_{t, n}^{a-} \geq 0$ and $Y_{t, n}^{a+}=0$, and he pays surrender charges on the amount $Y_{t, n}^{a-}$. The variable Withdraw $w_{t, n}^{a}$ is the actual amount the individual receives from sales of annuities.

Upon horizon $T$, conditional on being alive, the individual invests all the remaining wealth in the whole life annuities with fixed and constant payments. This behaviour is known in the literature as annuitization. The level of the annuity payments is equal to the consumption $C_{T}$, thus captured in the objective function and maximized. For all $n \in \mathcal{N}_{T}$ we have

$$
\begin{aligned}
0 & =\sum_{a \in \mathcal{A}} \operatorname{Withdraw}_{T, n}^{a}-\sum_{a \in \mathcal{A}^{\text {whole life }}} \operatorname{price}_{T, n}^{a} \text { Buy }_{T, n}^{a}\left(1+m e^{a}\right)+\sum_{a \notin \mathcal{A} \text { whole life }} c f_{T, n}^{a} \text { Hold }_{T, n}^{a} \\
& +\sum_{b \in \mathcal{B}} \operatorname{price}_{T, n}^{b} \operatorname{Sell}_{T, n}^{b}\left(1-t c^{b}\right)+\sum_{b \in \mathcal{B}} c f_{T, n}^{b} \operatorname{Hold}_{T, n}^{b} \\
& +\operatorname{price}_{T, n}^{s} \operatorname{Sell}_{T, n}^{s}\left(1-t c^{s}\right) \\
C_{T, n} & =\sum_{a \in \mathcal{A}_{\text {whole life }}} \operatorname{Hold}_{T, n}^{a} .
\end{aligned}
$$

The bequest amount is equal to the value of non-life contingent assets after rebalancing, i.e. stocks and bonds,

$$
W_{t, n}=\sum_{b \in \mathcal{B}}\left(\text { price }_{t, n}^{b}-c f_{t, n}^{b}\right) \operatorname{Hold}_{t, n}^{b}+\operatorname{price}_{t, n}^{s} \operatorname{Hold}_{t, n}^{s}, \quad t=t_{0} \ldots, T-1, n \in \mathcal{N}_{t}
$$

For each asset class we further define the inventory constraints,

$$
\text { Hold }_{t, n}^{i}=\text { Hold }_{t^{-}, n^{-}}^{i}+\text { Buy }_{t, n}^{i}-\text { Sell }_{t, n}^{i}, \quad t=t_{0}, \ldots, T, n \in \mathcal{N}_{t}, i \in\{\mathcal{A}, \mathcal{B}, \mathcal{S}\}
$$

with $B u y_{T, n}^{i}=0$, for $n \in \mathcal{N}_{T}$ and $i \in\{\mathcal{A}, \mathcal{B}, \mathcal{S}\} \backslash \mathcal{A}^{\text {whole life }}$, and impose non-negativity constraints on consumption, purchases, sales and hold variables,

$$
\begin{aligned}
& C_{t, n} \geq 0, \\
& \text { Buy }_{t, n}^{i} \geq 0, \text { Sell }_{t, n}^{i} \geq 0, \text { Hold }_{t, n}^{i} \geq 0 \text {, } \\
& t=t_{0}, \ldots, T, n \in \mathcal{N}_{t}, \\
& t=t_{0}, \ldots, T, n \in \mathcal{N}_{t}, i \in\{\mathcal{A}, \mathcal{B}, \mathcal{S}\} \text {. }
\end{aligned}
$$




\subsection{A two-person household model}

The multi-stage stochastic programming formulation for a two-person household is similar to the single case. The objective is to maximize the expected utility of consumption given both the wife and the husband are alive, and of the bequest in three possible situations: 1 . both the wife and the husband die, 2 . the wife is alive and the husband dies, and 3. the wife dies and the husband is alive. Therefore, by choosing parameters $k, k^{(x)}$ and $k^{(y)}$, we model the strength of the bequest motive for the heirs, or specifically for one of the spouses,

$$
\begin{aligned}
\max & \sum_{t=t_{0}}^{T} \sum_{n \in \mathcal{N}_{t}}{ }_{t} p_{x: y} \alpha_{t, n} u\left(t, C_{t, n}\right) \cdot \operatorname{prob}_{n}+\sum_{t=t_{0}}^{T-1} \sum_{n \in \mathcal{N}_{t}}{ }_{t} p_{x: y} q_{\overline{x+t: y+t}} k u\left(t, W_{t, n}\right) \cdot \operatorname{prob}_{n} \\
+ & \sum_{t=t_{0}}^{T-1} \sum_{n \in \mathcal{N}_{t}}{ }_{t} p_{x: y}\left(p_{x+t} q_{y+t} k^{(x)} u\left(t, W_{t, n}+A_{t, n}^{(x)}\right)+q_{x+t} p_{y+t} k^{(y)} u\left(t, W_{t, n}+A_{t, n}^{(y)}\right)\right) \cdot \text { prob }_{n} .
\end{aligned}
$$

Upon the husband's death, the wife inherits the value of stocks and bonds, and the value of pure endowments and annuities contingent on her life, i.e. single life and J\&S,

$$
A_{t, n}^{(x)}=\sum_{a \in \mathcal{A}^{l i f e, x}} \operatorname{price}_{t, n}^{a} \operatorname{Hold}_{t, n}^{a}, \quad t=t_{0}, \ldots, T-1, n \in \mathcal{N}_{t} .
$$

Upon the wife's death, similarly, the husband inherits $W_{t, n}+A_{t, n}^{(y)}$,

$$
A_{t, n}^{(y)}=\sum_{a \in \mathcal{A}^{l i f e, y}} \operatorname{price}_{t, n}^{a} \operatorname{Hold}_{t, n}^{a}, \quad t=t_{0}, \ldots, T-1, n \in \mathcal{N}_{t} .
$$

The terminal conditions (24)-25) ensure that if both spouses are alive upon horizon, they purchase one of the available whole life fixed annuities. Moreover, for ethical reasons, we add one more constraint implying that after the horizon both spouses should receive the same benefits,

$$
\sum_{a \in \mathcal{A}^{l i f e, x}} \operatorname{Hold}_{T, n}^{a}=\sum_{a \in \mathcal{A}^{l i f e, y}} \operatorname{Hold}_{T, n}^{a}, \quad n \in \mathcal{N}_{T},
$$

where the variable $\operatorname{Hold}_{T, n}^{a}$ includes the payments from pure endowments and annuities purchased during the entire period $\left[t_{0}, T\right]$.

Therefore, the model for the two-person household consists of the constraints for a single person household, i.e. $(19)-(29)$, and the constraints $(30)-(33)$.

\section{$5 \quad$ Numerical results}

The presented MSP formulation is a convex optimization problem with a nonlinear objective function and linear constraints. We implemented the program on a Dell computer with an Intel Core i5-2520M 2.50 GHZ processor and 4 GB RAM, using Matlab 8.2.0.713 (R2013b), and GAMS 24.1.3 with the non-linear solver MOSEK 7.0.0.75. We define 4 periods $(T=5)$ and use 5 -year decision steps $(\Delta t=5)$. The branching factor 
at each node is set to 10, thus, the optimal solution is based on 10,000 scenarios. The computational time varies between 1-6 minutes, depending on the choice of the parameters.

\subsection{Optimal decisions for a one-person household}

We start with analyzing the numerical results for a single female life. Our individual is 65 years old and, for the ease of presentation, has initial savings of $w_{0}=£ 100$. We use 4 decision stages with time intervals of 5 years, i.e. upon horizon $T$, the individual is 85 years old. Among the available assets we have stocks, zero coupon bonds with maturities 5, 10, 15 and 20 years, pure endowments with maturities 5, 10 and 15, and a whole life annuity deferred 20 years. Thus, the investment universe consists of 9 basic assets, which can be combined linearly to replicate the cash flows from more complex financial products. The maturities of the products are defined for the initial time $t_{0}$, and decrease with each period. Thus, any products maturing in $5,10,15$ or 20 years should be understood as maturing upon ages $70,75,80$, and 85 , respectively. As a result, the only available product upon the horizon is the whole life immediate annuity, which pays until the death of the individual. The individual has a possibility to trade the assets at any time before the horizon $T$, upon which the remaining wealth is annuitized. Transaction costs for stocks and bonds as well as M\&E charges are set to $1 \%$, and surrender charges are given in Table 1 . The time preference factor $\rho$ is set to $5 \%$.

Fixed annuities Figure 3 shows the optimal consumption and asset allocation for different levels of risk aversion and with and without a bequest motive. Parameters $\gamma=-5$ and $\gamma=-1$ describe a conservative and a more aggressive investor, respectively, whereas $k=0$ and $k=3^{1-\gamma}$ describe the person without and with a moderate bequest motive, respectively.

The yearly consumption in all the cases is around $7-7.5 \%$ of the initial savings $w_{0}$ upon retirement, and increases with time, because the time preference factor $\rho$ is lower than the expected return on the portfolio. The terminal condition upon age 85 implies that the individual annuitizes her wealth, therefore from age 85 until the death of the individual the consumption is constant. According to economic intuition, the less risk averse investor purchases products with a higher expected return, thus on average consumes more.

Independently of the level of risk aversion and the bequest motive, the investor gradually purchases a whole life annuity deferred upon age 85. The residual amount is distributed mostly between the pure endowment with a maturity of 15 years, zero coupon bonds with a maturity of 20 years, and stocks, however, the proportions between these assets differ with the level of risk aversion and the bequest motive. The investor has no need to purchase an immediate whole life annuity; she finances consumption during the first 15 years of retirement from the capital gains, and afterwards from pure endowments and deferred life annuities.

In the presence of a bequest motive a substantially higher amount is invested in stocks and bonds that partially replace the life contingent products. The overall wealth, and therefore also the potential bequest amount, decreases at each period as the individual consumes the savings. The more risk averse individual leaves a lower bequest amount to the heirs: $£ 30.4$ for the initial investment of $£ 100$, whereas the less risk averse person is more generous and invests $£ 48.1$ in the non-life contingent assets (for details see Table 7 in the Appendix).

The impact of surrender charges One may wonder how much the surrender charges affect the optimal portfolio. Our model allows for selling pure endowments and annuities, however such a sale is subject to 


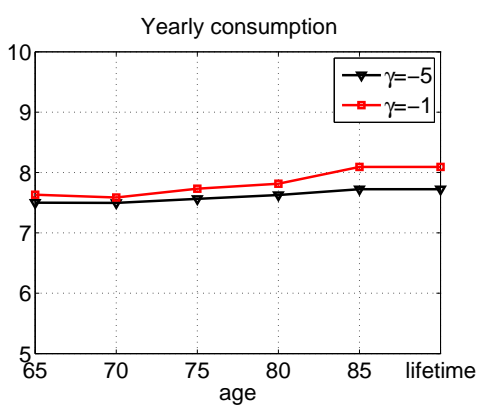

(a) $k=0$

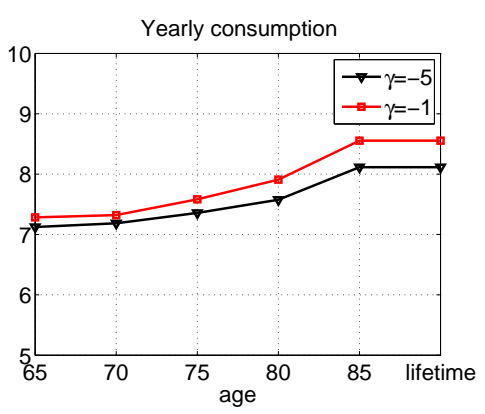

(d) $k=3^{1-\gamma}$

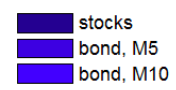

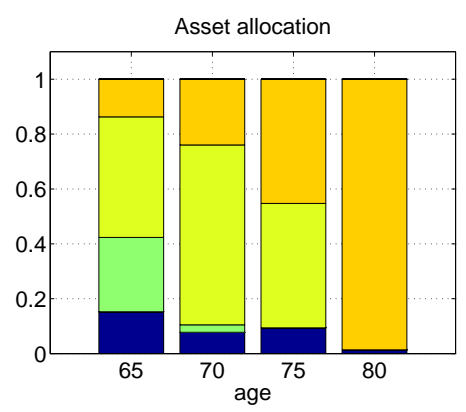

(b) $\gamma=-5, k=0$

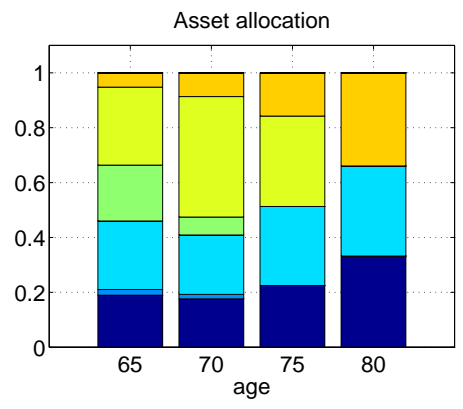

(e) $\gamma=-5, k=3^{1-\gamma}=729$

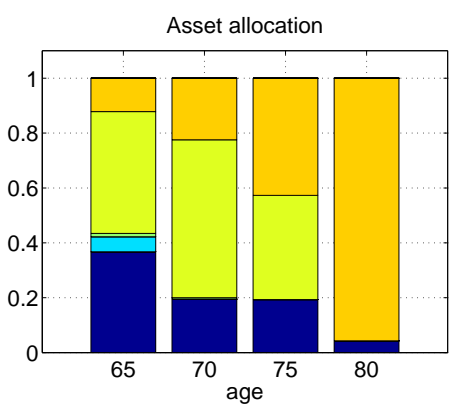

(c) $\gamma=-1, k=0$

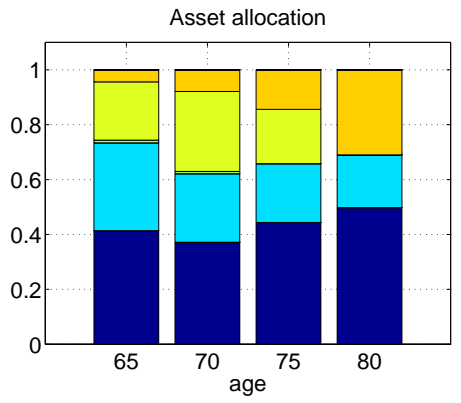

(f) $\gamma=-1, k=3^{1-\gamma}=9$
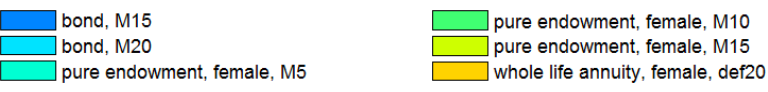

Figure 3: Optimal consumption and asset allocation for a single individual with no access to variable pure endowments (average across 10,000 scenarios). For details see Table 7 in the Appendix.

severe surrender charges, see Table 1. Not surprisingly, having removed the surrender charges, we find that the whole life annuities are even more attractive, and the individual without a bequest motive should always choose these products rather than bonds, see Fig. 4. On the contrary, Fig. 5 shows the solution from an optimization problem including the "no sale" constraints on pure endowments and annuities. Once these contracts are purchased, they can never be sold. In line with economic intuition the long term bonds play a more significant role in the optimal portfolio.

Variable pure endowments We expand the investment universe by adding variable pure endowments with maturities 5, 10, 15, and 20 years. The return on these products is equal to the return on stocks plus the survival credit, while the volatility is the same as for stocks. This makes variable pure endowments an attractive investment asset, and consequently the optimal portfolio includes these assets with all possible maturities. In particular, in the absence of a bequest motive the investor prioritizes the exceptionally high expected return on the variable pure endowments to more liquid stocks, and does not invest in stocks and bonds at all. The amount of the bequest is equal to 0, see Fig. 6 and Table 8 in the Appendix.

The high expected return on the portfolio implies that given initial savings of $£ 100$, the individual can afford the whole life annuity with the fixed payments of $£ 8.8$ for $\gamma=-5$, and $£ 10.1$ for $\gamma=-1$. Without the access to variable annuities, the corresponding fixed annuity payments are only $£ 7.7$ and $£ 8.1$ (see Tables 


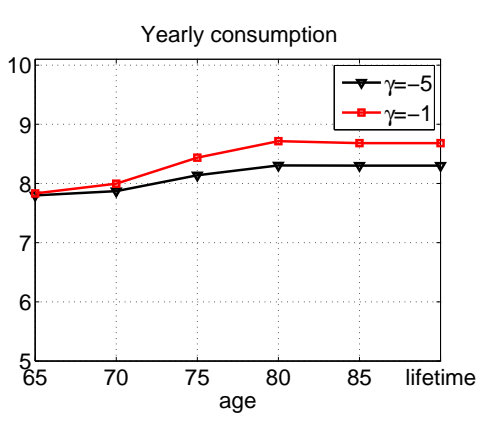

(a) $k=0$

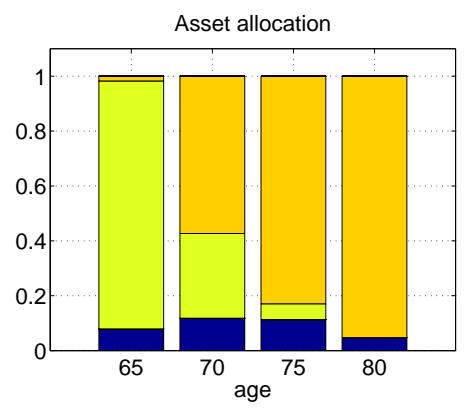

(b) $\gamma=-5, k=0$

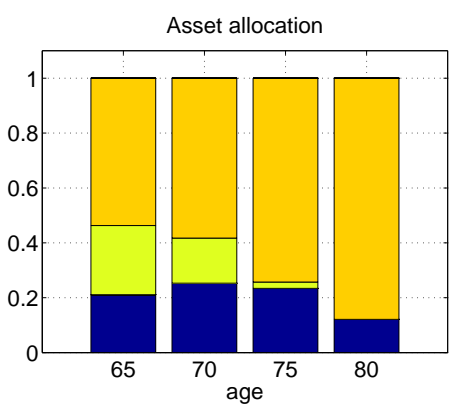

(c) $\gamma=-1, k=0$
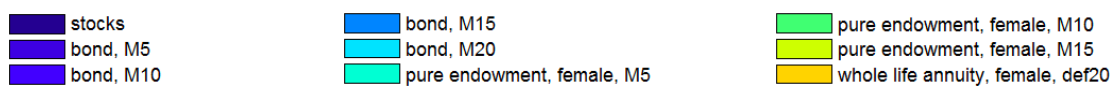

Figure 4: Optimal consumption and asset allocation for a single individual with no access to variable pure endowments. Assumed no surrender charges, M\&E charges, and transaction costs, i.e. $s c_{t}^{a}=0, m e^{a}=0$ and $t c^{b}=t c^{s}=0$ (average across 10,000 scenarios). For details see Table 7 in the Appendix.

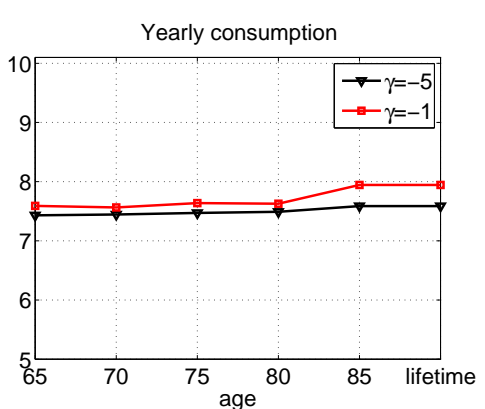

(a) $k=0$

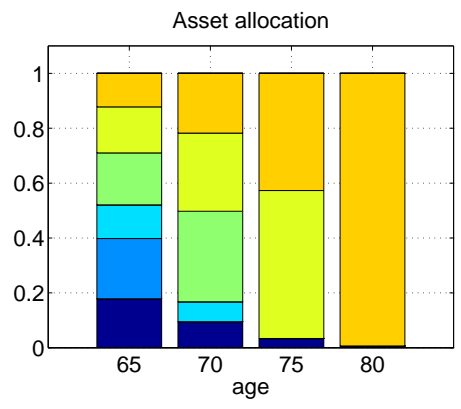

(b) $\gamma=-5, k=0$

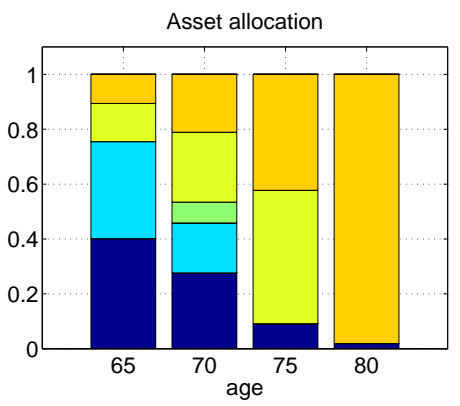

(c) $\gamma=-1, k=0$
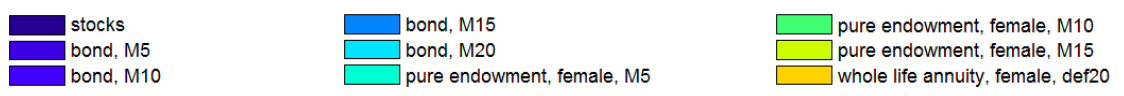

Figure 5: Optimal consumption and asset allocation for a one-person household with no access to variable pure endowments. The individual is not allowed to sell pure endowments and annuities, i.e. $f w^{a}=0$ and $s c_{t}^{a}=100 \%$ (average across 10,000 scenarios). For details see Table 7 in the Appendix.

7 and 8 in the Appendix). In the presence of a bequest motive, the investor still keeps a significant amount in variable pure endowments, but she diversifies the portfolio with non-life contingent assets, i.e. stocks and long term bonds.

\subsection{Optimal decisions for a two-person household}

This section analyzes the optimal solution for a two-person household. For the ease of presentation, we assume that both spouses are 65 years old upon retirement, and they have joint savings of $w_{0}=£ 100$. We extend the investment universe by adding pure endowments contingent on the husband's life (pure endowment, male) with maturities of 5, 10, and 15 years, and a single whole life annuity contingent on the husband's life 


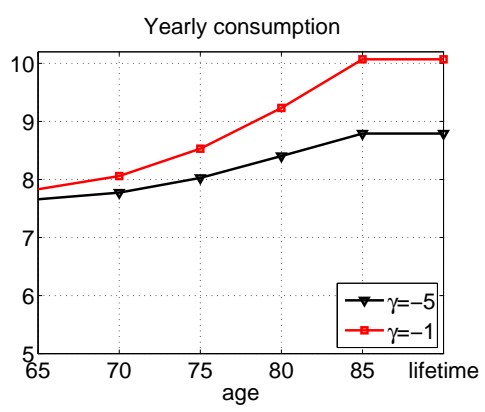

(a) $k=0$

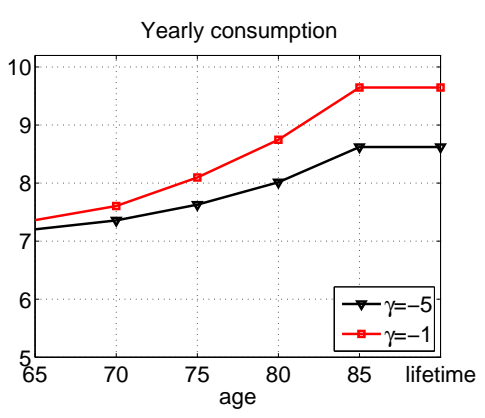

(d) $k=3^{1-\gamma}$

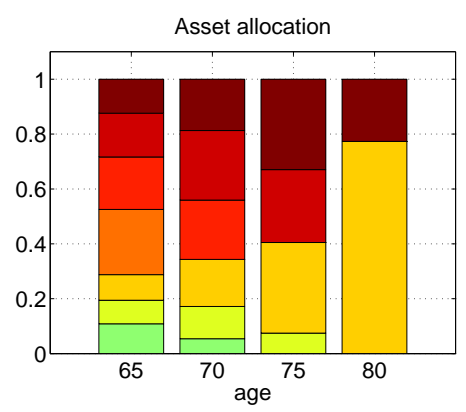

(b) $\gamma=-5, k=0$

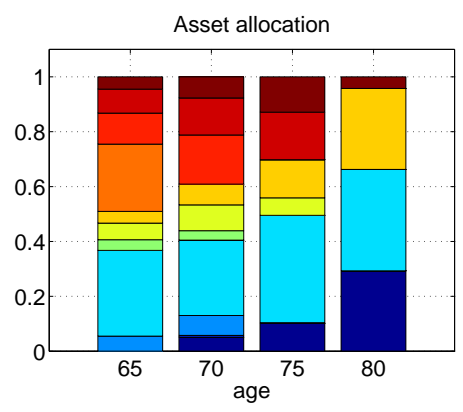

(e) $\gamma=-5, k=3^{1-\gamma}=729$

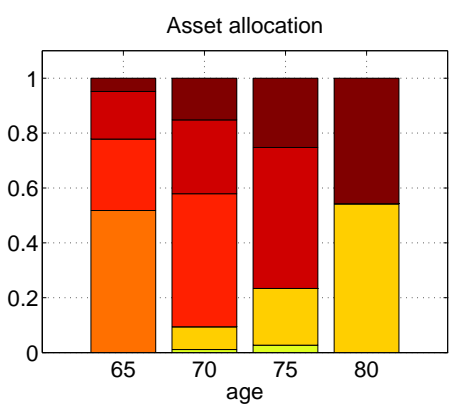

(c) $\gamma=-1, k=0$

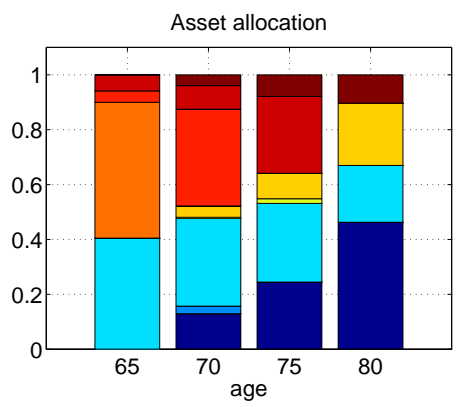

(f) $\gamma=-1, k=3^{1-\gamma}=9$

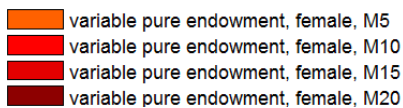

Figure 6: Optimal consumption and asset allocation for a single individual with access to variable pure endowments (average across 10,000 scenarios). For details see Table 8 in the Appendix.

deferred until age 85. We also add pure endowments contingent on the survival of at least one of the spouses (pure endowment, 100\% J\&S) with maturities 5, 10, 15, and 20 years 7 Furthermore, we add variable pure endowments, again contingent on each single life and on a joint life, and with maturities 5, 10, 15 and 20 years. Thus, we have in total 29 basic assets, which combined replicate a wide variety of annuities. Similarly as in the single case, the individuals have to annuitize any wealth in liquid assets upon horizon $T$, though in a way that the annuity payments for each spouse from time $T$ until death should be equal, as imposed by the terminal condition 33 .

Pure endowments contingent on the husband's life The couple (or, more specifically, the wife) takes advantage of the extended investment universe and heavily weights the portfolio by pure endowments contingent on the husband's life, see Figs. 7 and 8 . These products have a higher return than the annuities contingent on the wife's life or J\&S, while having the same financial risk, and are especially attractive with the variable payments. Therefore, in case of no bequest motive, the variable pure endowments contingent on the husband's life with all available maturities dominate the portfolio, see Figs. $8 \mathrm{~b}$ and $8 \mathrm{c}$. The residual amount is invested primarily in the single whole life annuities contingent on the wife's and the husband's life

\footnotetext{
${ }^{7}$ There is no need to include $Y \% \mathrm{~J} \& \mathrm{~S}$ pure endowments with $Y<100 \%$ because these are just a combination of two single life pure endowments and $100 \% \mathrm{~J} \& \mathrm{~S}$ pure endowment, see formula 7 .
} 
as enforced by the terminal condition.
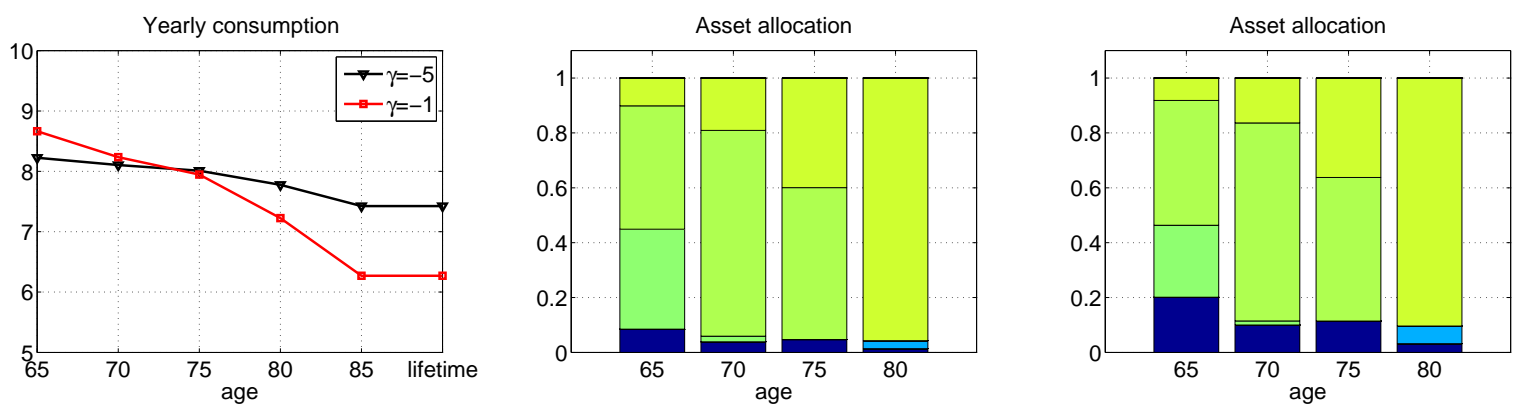

(a) $k=k^{(x)}=k^{(y)}=0$ $\gamma=\{-5,-1\}$

(b) $k=k^{(x)}=k^{(y)}=0$ $\gamma=-5$

(c) $k=k^{(x)}=k^{(y)}=0$
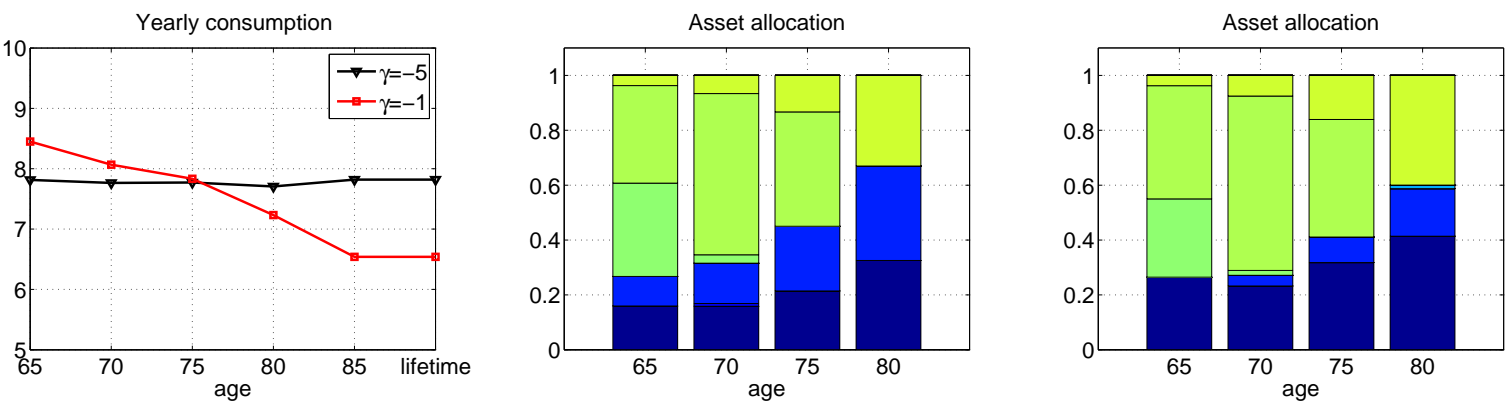

(d) $k=3^{1-\gamma}, k^{(x)}=k^{(y)}=0$

(e) $k=3^{1-\gamma}, k^{(x)}=k^{(y)}=0$
$\gamma=-5$

(f) $k=3^{1-\gamma}, k^{(x)}=k^{(y)}=0$
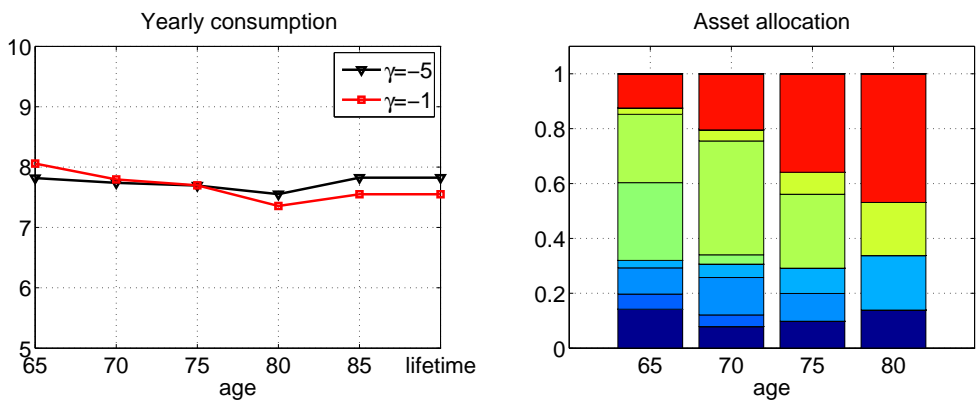

(g) $k=\underset{\gamma=\{-5,-1\}}{0, k^{(x)}}=k^{(y)}=3^{1-\gamma}$

(h) $k=0, k^{(x)}=k^{(y)}=3^{1-\gamma}$ $\gamma=-5$

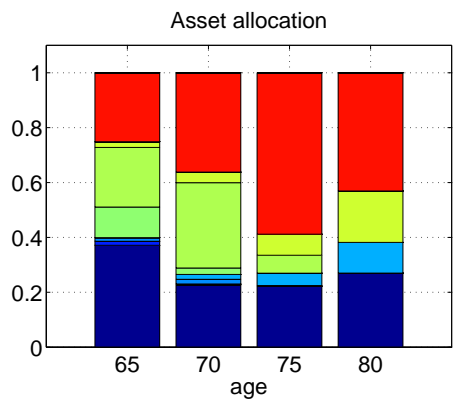

(i) $k=0, k^{(x)}=k^{(y)}=3^{1-\gamma}$ $\gamma=-1$
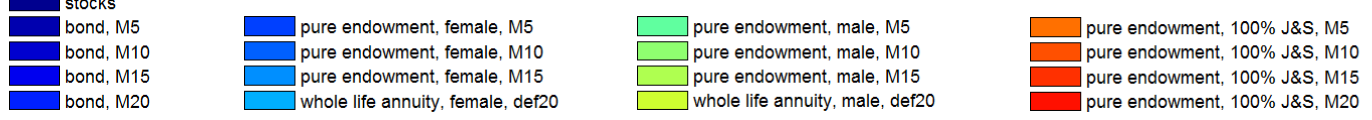

Figure 7: Optimal consumption and asset allocation for a two-person household with no access to variable pure endowments (average across 10,000 scenarios). For details see Table 9 in the Appendix.

Bequest motive We further consider three different settings. First, the couple has no bequest motive $\left(k=k^{(x)}=k^{(y)}=0\right)$; second, the couple has a moderate bequest motive for their heirs $\left(k=3^{1-\gamma}\right.$ and $k^{(x)}=k^{(y)}=0$ ); and third, the couple has a moderate bequest motive for the spouse but not for other 


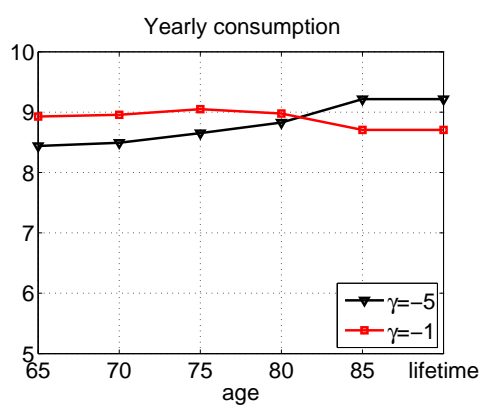

(a) $k=k^{(x)}=k^{(y)}=0$ $\gamma=\{-5,-1\}$

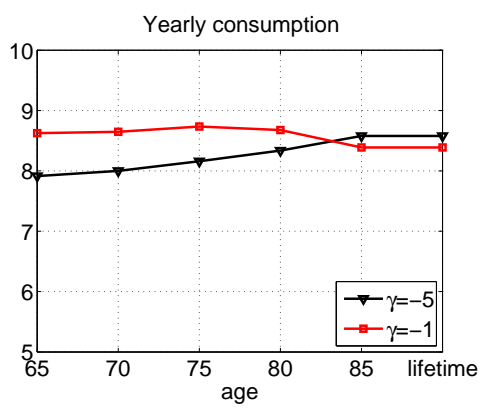

(d) $k=3^{1-\gamma}, k^{(x)}=k^{(y)}=0$ $\gamma=\{-5,-1\}$

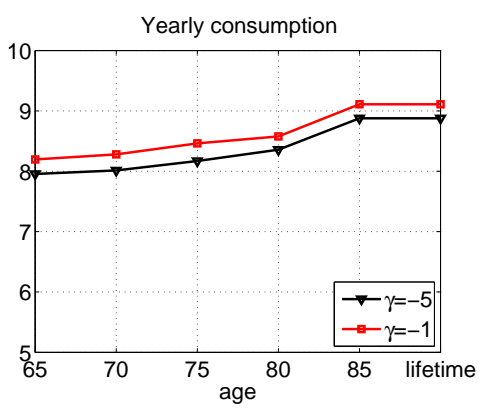

(g) $k=0, k^{(x)}=k^{(y)}=3^{1-\gamma}$ $\gamma=\{-5,-1\}$

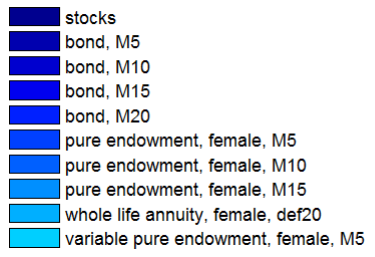

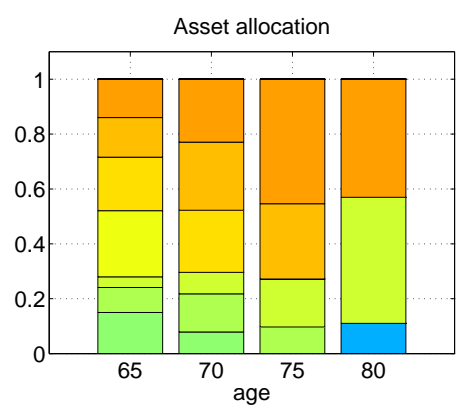

(b) $k=k^{(x)}=k^{(y)}=0$
$\gamma=-5$

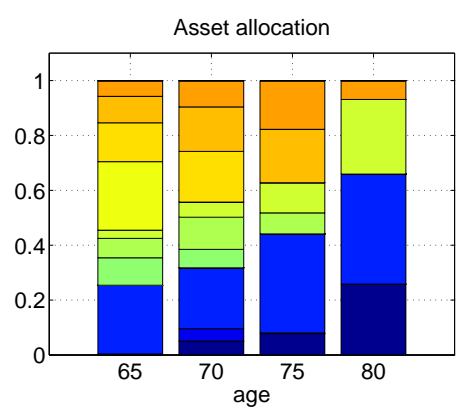

(e) $k=3^{1-\gamma}, k^{(x)}=k^{(y)}=0$ $\gamma=-5$

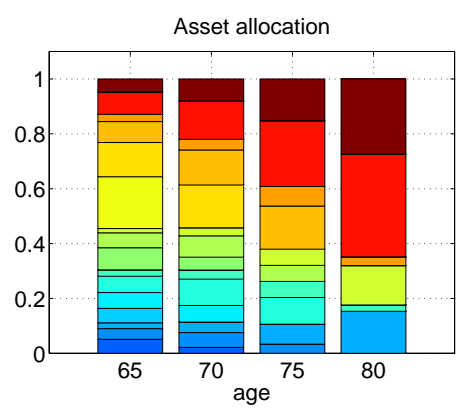

(h) $k=0, k^{(x)}=k^{(y)}=3^{1-\gamma}$ $\gamma=-5$

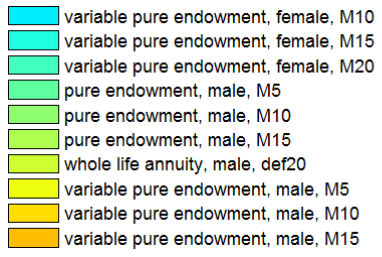

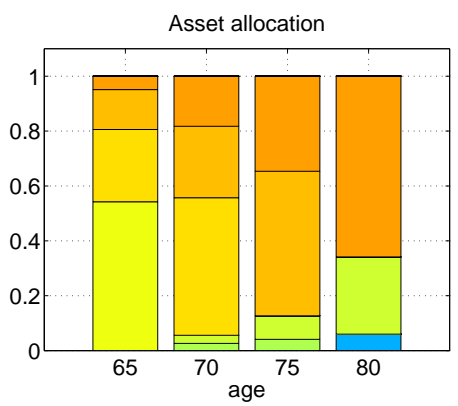

(c) $k=k^{(x)}=k^{(y)}=0$ $\gamma=-1$

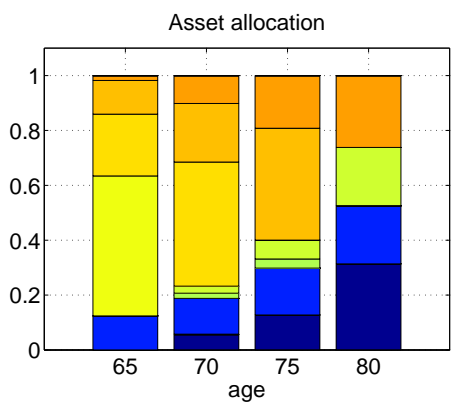

(f) $k=3^{1-\gamma}, k^{(x)}=k^{(y)}=0$ $\gamma=-1$

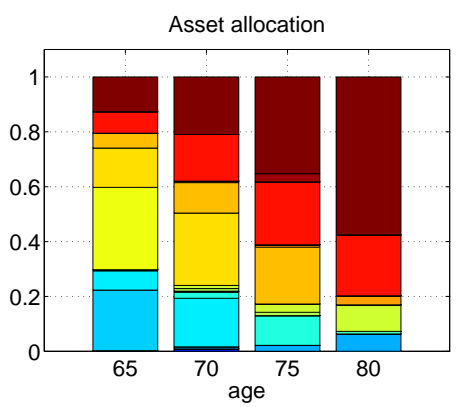

(i) $k=0, k^{(x)}=k^{(y)}=3^{1-\gamma}$ $\gamma=-1$

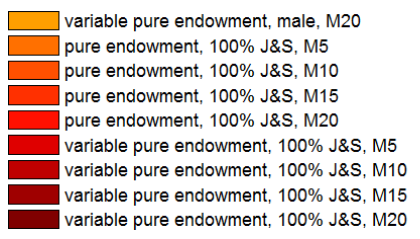

Figure 8: Optimal consumption and asset allocation for a two-person household with access to variable pure endowments (average across 10,000 scenarios). For details see Table 10 in the Appendix.

relatives $\left(k=0\right.$ and $\left.k^{(x)}=k^{(y)}=3^{1-\gamma}\right)$.

The three last rows in each section of Tables 9 and 10 show how the amount in inheritable assets changes with different choices of $k, k^{(x)}$ and $k^{(y)}$. If the couple has no bequest motive, their objective is simply to 
maximize the expected utility of consumption. Especially, having access to variable pure endowments, as seen in e.g. Figs. $8 \mathrm{~b}$ and $8 \mathrm{c}$, the couple does not hold any stocks or bonds, and the value of the bequest for the heirs is equal to 0 . The solution changes when the couple chooses to leave some money to the heirs. Then, they allocate more savings in stocks and bonds, see e.g. Figs. $8 \mathrm{e}$ and $8 \mathrm{f}$.

Notice that, independently of having access to variable pure endowments, the difference between the value of the bequest for the husband (the amount that the husband receives upon the wife's death, $W_{t, n}+A_{t, n}^{(y)}$ ) and the value of the bequest for the wife (the amount that the wife receives upon the husband's death, $\left.W_{t, n}+A_{t, n}^{(x)}\right)$ is significant. For the cases without a bequest motive, and with a moderate bequest motive for the heirs, the bequest for the wife and for the heirs is at a similar level, and is much lower than the bequest for the husband. Because the assets contingent on the husband's life have a higher expected return due to the higher mortality rate, they are always preferable to the assets contingent on the wife's life. Consequently, the couple invests heavily in the assets contingent on the husband's life, and upon the wife's death, the husband inherits most of the portfolio. This relation changes when the couple chooses to bequeath to the spouse. For example, for $k=0$ and $k^{(x)}=k^{(y)}=3^{1-\gamma}$, Table 10 in the Appendix shows a much higher bequest for the wife than in the previous cases, and the optimal portfolio includes some products contingent on the wife's life. This case is particularly interesting because the optimal portfolio consists of even 16 different products.

Joint and survivor products We do not explicitly include other J\&S products than $100 \%$ J\&S because we can replicate any $\mathrm{Y} \% \mathrm{~J} \& \mathrm{~S}$ pure endowment using eq. (7). At the first glance, one does not notice any J\&S pure endowments in the optimal portfolio. However, if both spouses survive until age 85, they will be receiving $£ 6.3$ as long as both are alive, and $£ 3.15$ if only one of them is alive (Table 9 , no bequest motive, $\gamma=-1$ ). Therefore, allocating $59 \%$ of the portfolio in the single annuity contingent on the wife's life and $41 \%$ in the single annuity contingent on the husband's life, is equivalent to allocating all the savings in the whole life $50 \%$ J\&S annuity.

Independently of the level of risk aversion and the bequest motive, the optimal investment strategy for the households always includes some Y\% J\&S pure endowments. For example, Figs. 7h and 7i show a certain percentage allocated to the $100 \%$ J\&S pure endowment, and Figs. 8h and $8 \mathrm{i}$ show further an allocation to the $100 \% \mathrm{~J} \& \mathrm{~S}$ variable pure endowment. Again, we can combine two single (variable) pure endowments and a $100 \%$ J\&S (variable) pure endowment into two products: a Y\% J\&S (variable) pure endowment and a single (variable) pure endowment. The optimal value of $Y$ changes dynamically at each period.

\subsection{Annuity product design}

To replicate more complex products offered by annuity providers, we can combine the basic assets used in this study: stocks, zero coupon bonds, and pure endowments with different maturities. We have shown how to replicate a $Y \%$ joint and survivor annuity given two single life annuities and a $100 \% \mathrm{~J} \& \mathrm{~S}$ annuity. Analogously, a combination of pure endowments with different maturities is equivalent to a life annuity with the size of the payments equal to the face value of the pure endowments; or a combination of zero coupon bonds and pure endowments with different maturities is nothing else than a life annuity with either a guaranteed period or a guaranteed amount.

The purpose of this paper is to build a model that could be applied for advising the households on choosing the annuity product that best fits their needs. There is no simple answer to this question. From the 
numerical results we see that it is never optimal to invest only in one product, even if it is relatively complex. It is not a question whether to choose a temporary single life annuity, a deferred $50 \% \mathrm{~J} \& \mathrm{~S}$ annuity, or an annuity with a guaranteed period. The optimal solution suggests a product that is much more complex that any of those existing in the market. A product that provides the cash flow equal to the optimal consumption as long as the individual or the couple is alive, and pays a death benefit equal to the optimal bequest amount. Because the model is based on the self financing portfolio (we do not allow for any additional income than the initial savings $w_{0}$, while the purchase of the assets is financed from the capital gains), the price of this product is $w_{0}$ upon retirement.

For example, to design a product for a couple with savings of $£ 100$, level or risk aversion $\gamma=-1$ and bequest motive for the spouse, i.e. $k=0$ and $k^{(x)}=k^{(y)}=3^{1-\gamma}$ (see Table 10 in the Appendix), we need an annuity with the expected payments increasing from $£ 8.2$ to $£ 9.1$ during the first 20 years of retirement, and constant afterwards. The payments are conditional on the survival of both spouses. Upon the death of one of the spouses, the survivor receives a death benefit - primarily in instalments. The expected death benefit declines with time: the husband inherits $\{£ 43.2, £ 39.9, £ 35.4, £ 28.0, £ 6.7\}$ if the wife dies between ages $\{65-70,70-75,75-80,80-85,85-120\}$, whereas the wife inherits $\{£ 30.8, £ 31.4, £ 31.1, £ 26.3, £ 9.8\}$ if the husband dies during the same years. Since the couple does not have a bequest motive for other dependants, if both spouses die there is nothing left for the dependants.

Such a product is a special case of a whole life $\mathrm{Y} \%$ joint and survivor annuity with variable and increasing payments, and with some life insurance attached. All the product parameters such as the portfolio backing the annuities, the rate defining the level of the benefit after the death of the first spouse $Y \%$, and the level of the bequest, are dynamic. They change with time, and the latter two are gender dependent.

\section{Conclusions}

In this paper we use a stochastic programming approach to help households choosing the right annuity product. Specifically, we derive the optimal asset allocation, consumption and bequest amount, given investment opportunities in stocks, zero coupon bonds and pure endowments with different maturities. The latter are contingent on either a single or joint life, and offer either fixed or variable payouts. We consider time-varying investment opportunities between stock market returns and interest rates, and use the Nelson/Siegel approach to represent the whole term structure of interest rates with a few factors. We further include transaction costs on stocks and bonds, as well as mortality and expense charges, and surrender charges on pure endowments and annuities.

Among other findings, we show that independently from the bequest motive and the level of risk aversion, it is optimal to diversify the portfolio in a wide variety of products. Despite high surrender charges, life contingent products are the primary asset class in the portfolio for the period after retirement. The annuity income, however, is never fully consumed, but used for rebalancing purposes. Especially variable pure endowments are attractive, since they provide a higher return than stocks while having the same volatility. Households can take advantage of the price differences between the gender-specific products and invest primarily in the products contingent on the husband's life and in the joint and survivor products. The weight on the bequest motive influences the amount of stocks and bonds in the portfolio.

We argue that the right product for a household is much more complex than any of the annuity products 
existing in the market. The optimal product has to be tailored to the specific needs of a household by carefully designing the optimal underlying portfolio, the expected cash flow, and the level of death benefit.

\section{References}

Ang, A., Bekaert, G. and Wei, M., Do Macro Variables, Asset Markets, or Surveys Forecast Inflation Better?. Journal of Monetary Economics, 2007, 54, 1163-1212.

Barberis, N.C., Investing for the Long Run when Returns are Predictable. The Journal of Finance, 2000, 55, $225-264$.

Boender, G., Dert, C., Heemskerk, F. and Hoek, H., 18: A Scenario Approach of ALM. In Handbook of Asset and Liability Management, pp. 829-861, 2005, Elsevier.

Brandt, M.W., Goyal, A., Santa-Clara, P. and Stroud, J.R., A Simulation Approach to Dynamic Portfolio Choice with an Application to Learning About Return Predictability. The Review of Financial Studies, 2005, 18, 831-873.

Bruhn, K. and Steffensen, M., Household Consumption, Investment and Life Insurance. Insurance: Mathematics and Economics, 2011, 48, 315-325.

Campbell, J.Y., Chan, Y.L. and Viceira, L.M., A Multivariate Model of Strategic Asset Allocation. Journal of Financial Economics, 2003, 67, 41-80.

Coroneo, L., Nyholm, K. and Vidova-Koleva, R., How Arbitrage-Free is the Nelson-Siegel Model?. Journal of Empirical Finance, 2011, 18, 393-407.

Dellinger, J.K., The Handbook of Variable Income Annuities, 2006, Hoboken, NJ : Wiley.

Diebold, F.X. and Li, C., Forecasting the Term Structure of Government Bond Yields. Journal of Econometrics, 2006, 130, 337-364.

Ferstl, R. and Weissensteiner, A., Asset-liability Management Under Time-varying Investment Opportunities. Journal of Banking $\mathscr{E}$ Finance, 2011, 35, 182 - 192.

Horneff, W.J., Maurer, R.H., Mitchell, O.S. and Stamos, M.Z., Asset Allocation and Location over the Life Cycle with Investment-linked Survival-contingent Payouts. Journal of Banking and Finance, 2009, 33, $1688-1699$.

Horneff, W., Maurer, R. and Rogalla, R., Dynamic Portfolio Choice with Deferred Annuities. Journal of Banking and Finance, 2010, 34, 2652-2664.

Horneff, W.J., Maurer, R.H. and Stamos, M.Z., Life-cycle Asset Allocation with Annuity Markets. Journal of Economic Dynamics and Control, 2008, 32, 3590-3612.

Høyland, K., Kaut, M. and Wallace, S.W., A Heuristic for Moment-Matching Scenario Generation. Computational Optimization and Applications, 2003, 24, 169-185.

Høyland, K. and Wallace, S.W., Generating Scenario Trees for Multistage Decision Problems. Management Science, 2001, 47, 295-307.

Hubener, A., Maurer, R. and Rogalla, R., Optimal Portfolio Choice with Annuities and Life Insurance for Retired Couples. Review of Finance, 2014, 18, 20147-188.

Konicz, A. and Mulvey, J.M., Applying a Stochastic Financial System for an Individual: Immediate or Deferred Life Annuities?. The Journal of Retirement, 2013, 1, 46-60. 
Konicz, A. and Mulvey, J.M., On Improving Pension Product Design. In Proceedings of the 30th Congress of Actuaries, Washington, DC. Available at http://www.staff.dtu.dk/agko/Research/ /media/agko/ paper_ICA_final.ashx, 2014.

Lütkepohl, H., Introduction to Multiple Time Series Analysis, 2005, Springer.

Milevsky and Young, Annuitization and Asset Allocation. Journal of Economic Dynamics and Control, 2007, 31, 3138-3177.

Mulvey, J.M., Simsek, K.D. and Pauling, W.R., A Stochastic Network Approach for Integrated Pension and Corporate Financial Planning. In Innovations in Financial and Economic Networks, edited by A. Nagurney, pp. 67-83, 2003, Edward Elgar Publishing, Cheltenham, UK.

Mulvey, J.M., Simsek, K.D., Zhang, Z., Fabozzi, F.J. and Pauling, W.R., Assisting Defined-Benefit Pension Plans. Operations Research, 2008, 56, 1066-1078.

Pedersen, A.M.B., Weissensteiner, A. and Poulsen, R., Financial Planning for Young Households. Annals of Operations Research, 2013, 205, 55-76.

Richard, S.F., Optimal Consumption, Portfolio and Life Insurance Rules for an Uncertain Lived Individual in a Continuous Time Model. Journal of Financial Economics, 1975, 2, 187-203.

Scott, J.S., Watson, J.G. and Hu, W., Efficient Annuitization: Optimal Strategies for Hedging Mortality Risk. Technical report PRC WP2007-09, Pension Research Council Working Paper, 2007.

Yaari, M.E., Uncertain Lifetime, Life Insurance, and the Theory of the Consumer. The Review of Economic Studies, 1965, 32, 137-150.

\section{Appendix}

The appendix provides the details for the numerical results and figures in Sec. 5 


\begin{tabular}{|c|c|c|c|c|c|c|c|c|c|c|}
\hline \multirow[b]{2}{*}{ assets/age } & \multicolumn{5}{|c|}{$\gamma=-5$} & \multicolumn{5}{|c|}{$\gamma=-1$} \\
\hline & 65 & 70 & 75 & 80 & 85 & 65 & 70 & 75 & 80 & 85 \\
\hline \multicolumn{11}{|l|}{ without a bequest motive, $k=0$} \\
\hline pure endowment, female, M10 & 27 & 3 & 0 & 0 & 0 & 1 & 1 & 0 & 0 & 0 \\
\hline pure endowment, female, M15 & 44 & 66 & 45 & 0 & 0 & 44 & 58 & 38 & 0 & 0 \\
\hline whole life annuity, female, def 20 & 14 & 24 & 45 & 99 & 100 & 12 & 22 & 43 & 96 & 100 \\
\hline consumption & $£ 7.5$ & $£ 7.5$ & $£ 7.6$ & $£ 7.6$ & $£ 7.7$ & $£ 7.6$ & $£ 7.6$ & $£ 7.7$ & $£ 7.8$ & $£ 8.1$ \\
\hline bequest & 9.8 & 4.2 & 4.0 & 0.3 & 0.0 & 27.0 & 10.2 & 8.1 & 1.0 & 0.0 \\
\hline \multicolumn{11}{|c|}{ without a bequest motive, $k=0$, no transaction costs, MESE charges and surrender charges } \\
\hline stocks & $8 \%$ & $12 \%$ & $11 \%$ & $5 \%$ & $0 \%$ & $21 \%$ & $25 \%$ & $23 \%$ & $12 \%$ & $0 \%$ \\
\hline pure endowment, female, M15 & 90 & 31 & 6 & 0 & 0 & 25 & 16 & 2 & 0 & 0 \\
\hline whole life annuity, female, def20 & 2 & 57 & 83 & 95 & 100 & 54 & 58 & 74 & 88 & 100 \\
\hline consumption & $£ 7.8$ & $£ 7.9$ & $£ 8.1$ & $£ 8.3$ & $£ 8.3$ & $£ 7.8$ & $£ 8.0$ & $£ 8.4$ & $£ 8.7$ & $£ 8.7$ \\
\hline bequest & 5.0 & 6.7 & 5.0 & 1.5 & 0.0 & 13.4 & 13.1 & 10.4 & 3.8 & 0.0 \\
\hline \multicolumn{11}{|c|}{ without a bequest motive, $k=0$, no sales constraints on annuities and pure endowments } \\
\hline stocks & $18 \%$ & $10 \%$ & $3 \%$ & $1 \%$ & $0 \%$ & $40 \%$ & $28 \%$ & $9 \%$ & $2 \%$ & $0 \%$ \\
\hline bond, M15 & 22 & 0 & 0 & 0 & 0 & 0 & 0 & 0 & 0 & 0 \\
\hline bond, M20 & 12 & 7 & 0 & 0 & 0 & 35 & 18 & 0 & 0 & 0 \\
\hline pure endowment, female, M10 & 19 & 33 & 0 & 0 & 0 & 0 & 8 & 0 & 0 & 0 \\
\hline female, M15 & 17 & 28 & 54 & 0 & 0 & 14 & 25 & 49 & 0 & 0 \\
\hline whole life annuity, female, def20 & 12 & 22 & 43 & 99 & 100 & 11 & 21 & 42 & 98 & 100 \\
\hline consumption & $£ 7.4$ & $£ 7.4$ & $£ 7.5$ & $£ 7.5$ & $£ 7.6$ & $£ 7.6$ & $£ 7.6$ & $£ 7.6$ & $£ 7.6$ & $£ 7.9$ \\
\hline bequest & 33.8 & 8.8 & 1.1 & 0.1 & 0.0 & 48.4 & 23.4 & 3.0 & 0.4 & 0.0 \\
\hline \multicolumn{11}{|c|}{ with a moderate bequest motive, $k=3^{1-\gamma}$} \\
\hline stocks & $19 \%$ & $18 \%$ & $22 \%$ & $33 \%$ & $0 \%$ & $41 \%$ & $37 \%$ & $44 \%$ & $50 \%$ & $0 \%$ \\
\hline bond, M15 & 2 & 2 & 0 & 0 & 0 & 0 & 0 & 0 & 0 & 0 \\
\hline bond, M20 & 25 & 22 & 29 & 33 & 0 & 32 & 25 & 21 & 19 & 0 \\
\hline nt, female, M10 & 20 & 7 & 0 & 0 & 0 & 1 & 1 & 0 & 0 & 0 \\
\hline pure endowm & 28 & 44 & 33 & 0 & 0 & 21 & 29 & 20 & 0 & 0 \\
\hline whole life annuity, female, def 20 & 5 & 9 & 16 & 34 & 100 & 4 & 8 & 14 & 31 & 100 \\
\hline ption & $£ 7.1$ & $£ 7.2$ & $£ 7.4$ & $£ 7.6$ & $£ 8.1$ & $£ 7.3$ & $£ 7.3$ & $£ 7.6$ & $£ 7.9$ & $£ 8.6$ \\
\hline bequest & 30.4 & 23.7 & 24.3 & 23.6 & 0.0 & 48.1 & 35.4 & 30.9 & 24.9 & 0.0 \\
\hline
\end{tabular}

Table 7: Optimal consumption, bequest and asset allocation for a one-person household (average across 10,000 scenarios). Assumed no access to variable pure endowments. 


\begin{tabular}{lrrrrr|r|rrrr}
\hline & \multicolumn{3}{c}{$\gamma=-5$} & \multicolumn{5}{c}{$\gamma=-1$} \\
assets/age & 65 & 70 & 75 & 80 & 85 & 65 & 70 & 75 & 80 & 85 \\
\hline without a bequest motive, $k=0$ & & & & & & & & & \\
pure endowment, female, M10 & $11 \%$ & $5 \%$ & $0 \%$ & $0 \%$ & $0 \%$ & $0 \%$ & $0 \%$ & $0 \%$ & $0 \%$ & $0 \%$ \\
pure endowment, female, M15 & 9 & 12 & 7 & 0 & 0 & 0 & 1 & 3 & 0 & 0 \\
whole life annuity, female, def20 & 9 & 17 & 33 & 77 & 100 & 0 & 8 & 21 & 54 & 100 \\
variable pure endowment, female, M5 & 24 & 0 & 0 & 0 & 0 & 52 & 0 & 0 & 0 & 0 \\
variable pure endowment, female, M10 & 19 & 22 & 0 & 0 & 0 & 26 & 49 & 0 & 0 & 0 \\
variable pure endowment, female, M15 & 16 & 25 & 27 & 0 & 0 & 17 & 27 & 51 & 0 & 0 \\
variable pure endowment, female, M20 & 12 & 19 & 33 & 23 & 0 & 5 & 15 & 25 & 46 & 0 \\
consumption & $£ 7.7$ & $£ 7.8$ & $£ 8.0$ & $£ 8.4$ & $£ 8.8$ & $£ 7.8$ & $£ 8.1$ & $£ 8.5$ & $£ 9.2$ & $£ 10.1$ \\
bequest & 0.0 & 0.0 & 0.0 & 0.0 & 0.0 & 0.0 & 0.0 & 0.0 & 0.0 & 0.0 \\
\hline with a moderate bequest motive, $k=31-\gamma$ & & & & & & & & & & \\
stocks & $0 \%$ & $5 \%$ & $10 \%$ & $29 \%$ & $0 \%$ & $0 \%$ & $13 \%$ & $24 \%$ & $46 \%$ & $0 \%$ \\
bond, M10 & 0 & 1 & 0 & 0 & 0 & 0 & 0 & 0 & 0 & 0 \\
bond, M15 & 6 & 7 & 0 & 0 & 0 & 0 & 3 & 0 & 0 & 0 \\
bond, M20 & 31 & 27 & 39 & 37 & 0 & 40 & 32 & 29 & 21 & 0 \\
pure endowment, female, M10 & 4 & 3 & 0 & 0 & 0 & 0 & 0 & 0 & 0 & 0 \\
pure endowment, female, M15 & 6 & 9 & 6 & 0 & 0 & 0 & 0 & 2 & 0 & 0 \\
whole life annuity, female, def20 & 4 & 8 & 14 & 30 & 100 & 0 & 4 & 9 & 23 & 100 \\
variable pure endowment, female, M5 & 25 & 0 & 0 & 0 & 0 & 49 & 0 & 0 & 0 & 0 \\
variable pure endowment, female, M10 & 11 & 18 & 0 & 0 & 0 & 4 & 35 & 0 & 0 & 0 \\
variable pure endowment, female, M15 & 9 & 14 & 17 & 0 & 0 & 6 & 9 & 28 & 0 & 0 \\
variable pure endowment, female, M20 & 4 & 8 & 13 & 4 & 0 & 0 & 4 & 8 & 10 & 0 \\
consumption & $£ 7.2$ & $£ 7.4$ & $£ 7.6$ & $£ 8.0$ & $£ 8.6$ & $£ 7.4$ & $£ 7.6$ & $£ 8.1$ & $£ 8.7$ & $£ 9.6$ \\
bequest & 24.2 & 23.4 & 23.2 & 24.5 & 0.0 & 26.4 & 26.1 & 25.2 & 25.7 & 0.0
\end{tabular}

Table 8: Optimal consumption, bequest and asset allocation for a one-person household (average across 10,000 scenarios). 


\begin{tabular}{|c|c|c|c|c|c|c|c|c|c|c|}
\hline \multirow[b]{2}{*}{ assets/age } & \multicolumn{5}{|c|}{$\gamma=-5$} & \multicolumn{5}{|c|}{$\gamma=-1$} \\
\hline & 65 & 70 & 75 & 80 & 85 & 65 & 70 & 75 & 80 & 85 \\
\hline \multicolumn{11}{|c|}{ without a bequest motive, $k=k^{(x)}=k^{(y)}=0$} \\
\hline stocks & $8 \%$ & $4 \%$ & $5 \%$ & $1 \%$ & $0 \%$ & $20 \%$ & $10 \%$ & $11 \%$ & $3 \%$ & $0 \%$ \\
\hline whole life annuity, female, def20 & 0 & 0 & 0 & 3 & 59 & 0 & 0 & 0 & 6 & 59 \\
\hline pure endowment, male, M10 & 36 & 2 & 0 & 0 & 0 & 26 & 1 & 0 & 0 & 0 \\
\hline pure endowment, male, M15 & 45 & 75 & 55 & 0 & 0 & 45 & 72 & 52 & 0 & 0 \\
\hline whole life annuity, male, def20 & 10 & 19 & 40 & 96 & 41 & 8 & 16 & 36 & 90 & 41 \\
\hline consumption & $£ 8.2$ & $£ 8.1$ & $£ 8.0$ & $£ 7.8$ & $£ 7.4$ & $£ 8.7$ & $£ 8.2$ & $£ 7.9$ & $£ 7.2$ & $£ 6.3$ \\
\hline bequest for the husband, $W_{t}+A_{t}^{(y)}$ & 61.1 & 48.5 & 35.2 & 23.1 & 5.4 & 59.1 & 45.2 & 31.0 & 18.5 & 4.6 \\
\hline bequest for the wife, $W_{t}+A_{t}^{(x)}$ & 5.2 & 2.1 & 1.7 & 1.0 & 8.0 & 11.9 & 4.9 & 3.6 & 1.9 & 6.7 \\
\hline bequest for the heirs, $W_{t}$ & 5.2 & 2.1 & 1.7 & 0.3 & 0.0 & 11.9 & 4.9 & 3.6 & 0.5 & 0.0 \\
\hline \multicolumn{11}{|c|}{ with a moderate bequest motive, $k=3^{1-\gamma}, k^{(x)}=k^{(y)}=0$} \\
\hline stocks & $16 \%$ & $16 \%$ & $21 \%$ & $33 \%$ & $0 \%$ & $26 \%$ & $23 \%$ & $32 \%$ & $41 \%$ & $0 \%$ \\
\hline bond, M20 & 11 & 15 & 24 & 34 & 0 & 0 & 4 & 9 & 17 & 0 \\
\hline whole life annuity, female, def20 & 0 & 0 & 0 & 0 & 59 & 0 & 0 & 0 & 1 & 59 \\
\hline pure endowment, male, M10 & 34 & 3 & 0 & 0 & 0 & 29 & 2 & 0 & 0 & 0 \\
\hline pure endowment, male, M15 & 36 & 59 & 42 & 0 & 0 & 41 & 64 & 43 & 0 & 0 \\
\hline whole life annuity, male, def20 & 4 & 7 & 13 & 33 & 41 & 4 & 8 & 16 & 40 & 41 \\
\hline consumption & $£ 7.8$ & $£ 7.8$ & $£ 7.8$ & $£ 7.7$ & $£ 7.8$ & $£ 8.5$ & $£ 8.1$ & $£ 7.8$ & $£ 7.2$ & $£ 6.5$ \\
\hline bequest for the husband, $W_{t}+A_{t}^{(y)}$ & 63.0 & 52.2 & 40.8 & 29.3 & 5.7 & 60.1 & 47.3 & 34.5 & 23.6 & 4.8 \\
\hline bequest for the wife, $W_{t}+A_{t}^{(x)}$ & 16.8 & 18.2 & 20.0 & 20.8 & 8.4 & 15.9 & 13.8 & 15.2 & 15.5 & 7.0 \\
\hline bequest for the heirs, $W_{t}$ & 16.8 & 18.2 & 20.0 & 20.8 & 0.0 & 15.9 & 13.8 & 15.2 & 15.1 & 0.0 \\
\hline \multicolumn{11}{|c|}{ with a moderate bequest motive for the spouse, $k=0, k^{(x)}=k^{(y)}=3^{1-\gamma}$} \\
\hline stocks & $14 \%$ & $8 \%$ & $10 \%$ & $14 \%$ & $0 \%$ & $37 \%$ & $23 \%$ & $22 \%$ & $27 \%$ & $0 \%$ \\
\hline pure endowment, female, M10 & 6 & 4 & 0 & 0 & 0 & 0 & 0 & 0 & 0 & 0 \\
\hline pure endowment, female, M15 & 10 & 14 & 10 & 0 & 0 & 1 & 2 & 0 & 0 & 0 \\
\hline whole life annuity, female, def20 & 3 & 5 & 9 & 20 & 59 & 0 & 2 & 4 & 11 & 59 \\
\hline pure endowment, male, M10 & 28 & 3 & 0 & 0 & 0 & 11 & 2 & 0 & 0 & 0 \\
\hline pure endowment, male, M15 & 25 & 42 & 27 & 0 & 0 & 22 & 31 & 7 & 0 & 0 \\
\hline whole life annuity, male, def 20 & 2 & 4 & 8 & 19 & 41 & 2 & 4 & 8 & 19 & 41 \\
\hline pure endowment, $100 \%$ J\&S, M20 & 12 & 20 & 36 & 47 & 0 & 25 & 36 & 59 & 43 & 0 \\
\hline consumption & $£ 7.8$ & $£ 7.7$ & $£ 7.7$ & $£ 7.6$ & $£ 7.8$ & $£ 8.1$ & $£ 7.8$ & $£ 7.7$ & $£ 7.4$ & $£ 7.6$ \\
\hline bequest for the husband, $W_{t}+A_{t}^{(y)}$ & 51.8 & 40.0 & 32.1 & 22.7 & 5.7 & 61.1 & 47.7 & 36.4 & 24.1 & 5.5 \\
\hline bequest for the wife, $W_{t}+A_{t}^{(x)}$ & 28.0 & 27.4 & 26.8 & 23.4 & 8.4 & 40.3 & 32.7 & 34.4 & 22.8 & 8.1 \\
\hline bequest for the heirs, $W_{t}$ & 8.9 & 4.2 & 4.1 & 4.3 & 0.0 & 23.9 & 11.3 & 8.4 & 7.6 & 0.0 \\
\hline
\end{tabular}

Table 9: Optimal consumption, bequest and asset allocation for a two-person household (average across 10,000 scenarios). Assumed no access to variable pure endowments. 


\begin{tabular}{|c|c|c|c|c|c|c|c|c|c|c|}
\hline \multirow[b]{2}{*}{ assets/age } & \multicolumn{5}{|c|}{$\gamma=-5$} & \multicolumn{5}{|c|}{$\gamma=-1$} \\
\hline & 65 & 70 & 75 & 80 & 85 & 65 & 70 & 75 & 80 & 85 \\
\hline \multicolumn{11}{|l|}{ without a bequest motive, $k=k^{(x)}=k^{(y)}=0$} \\
\hline whole life annuity, female, def 20 & $0 \%$ & $0 \%$ & $0 \%$ & $11 \%$ & $59 \%$ & $0 \%$ & $0 \%$ & $0 \%$ & $6 \%$ & $59 \%$ \\
\hline pure endowment, male, M10 & 15 & 8 & 0 & 0 & 0 & 0 & 0 & 0 & 0 & 0 \\
\hline pure endowment, male, M15 & 9 & 14 & 10 & 0 & 0 & 0 & 3 & 4 & 0 & 0 \\
\hline whole life annuity, male, def 20 & 4 & 8 & 17 & 46 & 41 & 0 & 3 & 9 & 28 & 41 \\
\hline variable pure endowment, male, M5 & 24 & 0 & 0 & 0 & 0 & 54 & 0 & 0 & 0 & 0 \\
\hline variable pure endowment, male, M10 & 20 & 23 & 0 & 0 & 0 & 26 & 50 & 0 & 0 & 0 \\
\hline variable pure endowment, male, M15 & 14 & 25 & 27 & 0 & 0 & 15 & 26 & 53 & 0 & 0 \\
\hline variable pure endowment, male, M20 & 14 & 23 & 45 & 43 & 0 & 5 & 18 & 35 & 66 & 0 \\
\hline consumption & $£ 8.4$ & $£ 8.5$ & $£ 8.7$ & $£ 8.8$ & $£ 9.2$ & $£ 8.9$ & $£ 9.0$ & $£ 9.0$ & $£ 9.0$ & $£ 8.7$ \\
\hline bequest for the husband, $W_{t}+A_{t}^{(y)}$ & 60.1 & 47.3 & 34.7 & 21.5 & 6.8 & 57.9 & 44.1 & 31.7 & 20.3 & 6.4 \\
\hline bequest for the wife, $W_{t}+A_{t}^{(x)}$ & 0.0 & 0.0 & 0.0 & 3.1 & 9.9 & 0.0 & 0.0 & 0.0 & 1.6 & 9.4 \\
\hline bequest for the heirs, $W_{t}$ & 0.0 & 0.0 & 0.0 & 0.0 & 0.0 & 0.0 & 0.0 & 0.0 & 0.0 & 0.0 \\
\hline \multicolumn{11}{|c|}{ with a moderate bequest motive, $k=3^{1-\gamma}, k^{(x)}=k^{(y)}=0$} \\
\hline stocks & $0 \%$ & $5 \%$ & $8 \%$ & $26 \%$ & $0 \%$ & $0 \%$ & $6 \%$ & $13 \%$ & $31 \%$ & $0 \%$ \\
\hline bond, M15 & 0 & 5 & 0 & 0 & 0 & 0 & 0 & 0 & 0 & 0 \\
\hline bond, M20 & 25 & 22 & 36 & 40 & 0 & 12 & 13 & 17 & 21 & 0 \\
\hline whole life annuity, female, def20 & 0 & 0 & 0 & 0 & 59 & 0 & 0 & 0 & 0 & 59 \\
\hline pure endowment, male, M10 & 10 & 7 & 0 & 0 & 0 & 0 & 0 & 0 & 0 & 0 \\
\hline pure endowment, male, M15 & 7 & 12 & 8 & 0 & 0 & 0 & 2 & 3 & 0 & 0 \\
\hline whole life annuity, male, def 20 & 3 & 6 & 11 & 27 & 41 & 0 & 3 & 7 & 21 & 41 \\
\hline variable pure endowment, male, M5 & 25 & 0 & 0 & 0 & 0 & 51 & 0 & 0 & 0 & 0 \\
\hline variable pure endowment, male, M10 & 14 & 18 & 0 & 0 & 0 & 23 & 45 & 0 & 0 & 0 \\
\hline variable pure endowment, male, M15 & 10 & 16 & 19 & 0 & 0 & 12 & 21 & 41 & 0 & 0 \\
\hline variable pure endowment, male, M20 & 6 & 10 & 18 & 7 & 0 & 2 & 10 & 19 & 26 & 0 \\
\hline consumption & $£ 7.9$ & $£ 8.0$ & $£ 8.2$ & $£ 8.3$ & $£ 8.6$ & $£ 8.6$ & $£ 8.6$ & $£ 8.7$ & $£ 8.7$ & $£ 8.4$ \\
\hline bequest for the husband, $W_{t}+A_{t}^{(y)}$ & 62.6 & 52.0 & 41.1 & 31.0 & 6.3 & 59.3 & 46.4 & 35.7 & 26.2 & 6.2 \\
\hline bequest for the wife, $W_{t}+A_{t}^{(x)}$ & 15.9 & 18.0 & 19.1 & 21.4 & 9.2 & 7.4 & 9.5 & 11.3 & 14.5 & 9.0 \\
\hline bequest for the heirs, $W_{t}$ & 15.9 & 18.0 & 19.1 & 21.4 & 0.0 & 7.4 & 9.5 & 11.3 & 14.4 & 0.0 \\
\hline \multicolumn{11}{|c|}{ with a moderate bequest motive for the spouse, $k=0, k^{(x)}=k^{(y)}=3^{1-\gamma}$} \\
\hline pure endowment, female, M10 & $5 \%$ & $2 \%$ & $0 \%$ & $0 \%$ & $0 \%$ & $0 \%$ & $0 \%$ & $0 \%$ & $0 \%$ & $0 \%$ \\
\hline pure endowment, female, M15 & 4 & 5 & 3 & 0 & 0 & 0 & 0 & 0 & 0 & 0 \\
\hline whole life annuity, female, def20 & 2 & 4 & 7 & 15 & 59 & 0 & 1 & 2 & 6 & 59 \\
\hline variable pure endowment, female, M5 & 5 & 0 & 0 & 0 & 0 & 22 & 0 & 0 & 0 & 0 \\
\hline variable pure endowment, female, M10 & 6 & 6 & 0 & 0 & 0 & 7 & 18 & 0 & 0 & 0 \\
\hline variable pure endowment, female, M15 & 6 & 10 & 10 & 0 & 0 & 0 & 2 & 11 & 0 & 0 \\
\hline variable pure endowment, female, M20 & 2 & 3 & 6 & 2 & 0 & 0 & 0 & 0 & 1 & 0 \\
\hline pure endowment, male, M15 & 5 & 8 & 6 & 0 & 0 & 0 & 1 & 1 & 0 & 0 \\
\hline whole life annuity, male, def 20 & 2 & 3 & 6 & 14 & 41 & 0 & 1 & 3 & 10 & 41 \\
\hline variable pure endowment, male, M5 & 19 & 0 & 0 & 0 & 0 & 30 & 0 & 0 & 0 & 0 \\
\hline variable pure endowment, male, M10 & 12 & 16 & 0 & 0 & 0 & 14 & 26 & 0 & 0 & 0 \\
\hline variable pure endowment, male, M15 & 8 & 13 & 16 & 0 & 0 & 5 & 11 & 21 & 0 & 0 \\
\hline variable pure endowment, male, M20 & 3 & 4 & 7 & 3 & 0 & 0 & 1 & 1 & 3 & 0 \\
\hline pure endowment, $100 \% \mathrm{~J} \& \mathrm{~S}, \mathrm{M} 20$ & 8 & 14 & 24 & 37 & 0 & 8 & 17 & 23 & 22 & 0 \\
\hline variable pure endowment, $100 \% \mathrm{~J} \& \mathrm{~S}, \mathrm{M} 15$ & 0 & 0 & 0 & 0 & 0 & 0 & 0 & 3 & 0 & 0 \\
\hline variable pure endowment, $100 \% \mathrm{~J} \& \mathrm{~S}, \mathrm{M} 20$ & 5 & 8 & 15 & 27 & 0 & 13 & 21 & 35 & 58 & 0 \\
\hline consumption & $£ 8.0$ & $£ 8.0$ & $£ 8.2$ & $£ 8.4$ & $£ 8.9$ & $£ 8.2$ & $£ 8.3$ & $£ 8.5$ & $£ 8.6$ & $£ 9.1$ \\
\hline bequest for the husband, $W_{t}+A_{t}^{(y)}$ & 43.4 & 35.9 & 29.8 & 24.9 & 6.5 & 43.2 & 39.9 & 35.4 & 28.0 & 6.7 \\
\hline bequest for the wife, $W_{t}+A_{t}^{(x)}$ & 27.0 & 27.5 & 26.9 & 25.0 & 9.6 & 30.8 & 31.4 & 31.1 & 26.3 & 9.8 \\
\hline bequest for the heirs, $W_{t}$ & 0.0 & 0.0 & 0.0 & 0.0 & 0.0 & 0.1 & 0.6 & 0.0 & 0.0 & 0.0 \\
\hline
\end{tabular}

Table 10: Optimal consumption, bequest and asset allocation for a two-person household (average across 10,000 scenarios). 